ST VINCENT'S PSYCHIATRIC EMERGENCY CARE CENTRE:

AN EVALUATION OF A NURSE-LED SERVICE

by

Caroline H Koia

A thesis submitted to the Victoria University of Wellington

in fulfilment of the

requirements for the degree of

Master of Nursing (Clinical)

Victoria University of Wellington

2009 
Abstract

Australia, like many other countries that adopted deinstitutionalisation is experiencing increased presentation at emergency departments (EDs) by patients with acute mental health and addiction needs. While different models of psychiatric emergency care have been utilised within EDs little is known about the effectiveness of the care provided or how they work on a day-to-day basis. Psychiatric Emergency Care Centres (PECCs) is one of these new initiatives. PECCs aim to improve patient flow in urban EDs by providing a rapid pathway to specialist mental health assessment and care. St Vincent hospital in Sydney opened a 6 bed PECC service in 2005. It is co-located with ED and staffed 24 hours a day by registered mental health nurses supported by psychiatric and emergency teams. The service has two components - a short term stay unit and an ED liaison role. The nurses work closely with community mental health teams, inpatient units, general practitioners, non-government agencies and other hospitals. This thesis evaluated the organisational and operational aspects of this PECC service using a processimpact evaluation. Documents, existing clinical records and interviews with nurses in the PECC and ED and with a consumer representative were used as data sources to describe the service and identify what was working well and what could be improved. The research found that the service has provided additional resources and collaboration between ED and mental health services. In addition the research found that PECC is an effective service catering to the needs of consumers and providing access to mental health specialist clinicians. Since PECC was established there has been an increase in assessments conducted within the ED and an increase in the numbers presenting to ED for mental health reasons from 2833 in 2006 to 4987 in 2008, but the number of admissions to PECC have remained relatively stable at 693 and 714. Aspects of the service that worked well included the rapid assessment and management of acutely unwell people by the PECC nurses. Aspects that were problematic concerned the ability of the service to address social issues and the management of people with behavioural, alcohol, substance intoxication or selfharm behaviours. Areas for enhancing the service include being more consumers 
responsive, increasing the skills and knowledge of staff and undertaking further research regarding the needs of people who use the service.

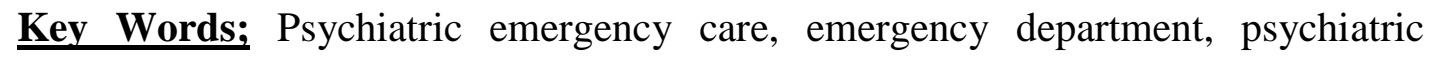
emergency care centres, mental health nursing. 


\section{Dedication}

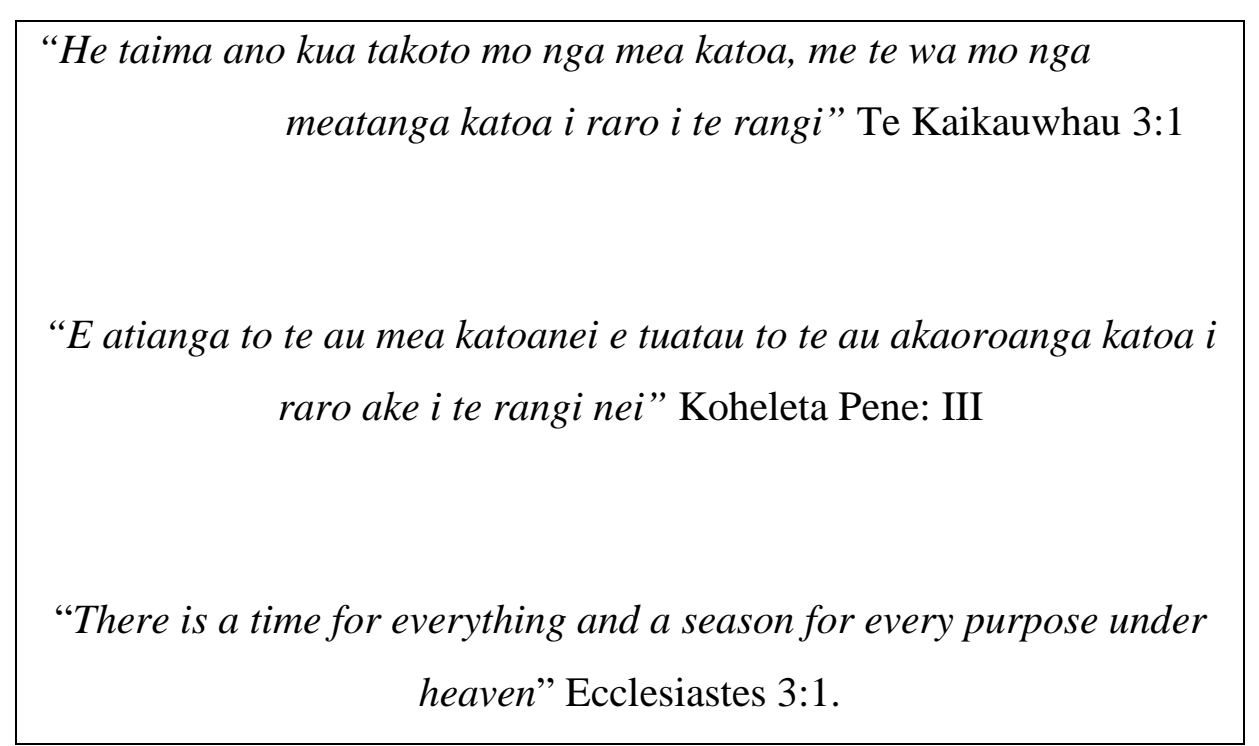

I dedicate this thesis to the memory of Te Aute Kareti Karangapapa Papuni (my Dad), Uraaii Te'A Papuni (my Mother) and also to Eru Kurei (my brother) whose untimely passing coincided with my move to Sydney. I miss you all.

He pupū ana te aroha e kai kino nei $i$ roto $i$ te ngakau. Moe mai ra koutou $i$ runga $i$ nga ringa o to tatou Ariki. 


\section{Acknowledgements}

To all my whanau who have been with me on my academic learning journeys, thank you for your love, support, latte and for not leaving me to struggle alone. It is your own achievements and struggles that have inspired me to complete this thesis. Please keep the lattes coming.

To my colleagues in PECC, ED and the Consumer Participation Representative, thank you all for your valuable contribution to this thesis. In exchange for your participation and shared knowledge, I give you this thesis as a gift of my appreciation.

To Jem Masters, thank you for your assistance with technical issues regarding computer graphics and statistical analysis.

To Beaver Hudson, thank you for your support. It was your vision which created the basis of this thesis. It is your sharing of knowledge, information, resources and moral support which helped me throughout my Masters year of study.

To Kathy Nelson, thank you for your ongoing supervision and patience which has been invaluable in guiding me through this thesis.

Finally to Marg Adamson, thank you for your encouragement, moral support and sharing of knowledge which has helped me through this journey. 


\section{Table of Contents}

$\begin{array}{lll}\text { ABSTRACT } & \text { ii }\end{array}$

DEDICATION iv

ACKNOWLEDGEMENTS $\quad \mathrm{v}$

TABLE OF CONTENTS vi

LIST OF TABLES $\quad x$

LIST OF FIGURES $\quad$ x

CHAPTER 1 - INTRODUCTION 1

$\begin{array}{ll}\text { Background } & 1\end{array}$

The study 3

Overview of the research 3

Introduction to researcher 4

Overview of Psychiatric Emergency Care Centre Services 6

$\begin{array}{ll}\text { Thesis overview } & 7\end{array}$

CHAPTER 2 - LITERATURE REVIEW 9

Introduction 9

$\begin{array}{ll}\text { Search strategy } & 9\end{array}$

$\begin{array}{ll}\text { Overview of the literature } & 10\end{array}$

Overview of Psychiatric Emergency Care Services in Emergency

$\begin{array}{ll}\text { Departments } & 11\end{array}$ 
Consultation Liaison Model of Care 12

Mental Health Nurse in Emergency Department 17

Psychiatric Emergency Care Centre Model of Care 20

$\begin{array}{ll}\text { Discussion } & 24\end{array}$

$\begin{array}{ll}\text { Conclusion } & 26\end{array}$

CHAPTER 3 - DESCRIPTION OF THE PSYCHIATRIC EMERGENCY CARE

$\begin{array}{ll}\text { SERVICE } & 27\end{array}$

$\begin{array}{ll}\text { Introduction } & 27\end{array}$

Description of Psychiatric Emergency Care Centres 28

St Vincent's Psychiatric Emergency Care Centre 29

St Vincent's Psychiatric Emergency Care Centre Model of Care 30

The clinical team 31

The patient's journey $\quad 34$

$\begin{array}{ll}\text { Documentation in patient's notes } & 37\end{array}$

$\begin{array}{ll}\text { Security Service } & 38\end{array}$

Triage process to Emergency Department 38

Admission process to Psychiatric Emergency Care Centre 40

Mental health presentations to Emergency Department and Psychiatric

Emergency Care Centre $\quad 42$

Bed management $\quad 44$

Role effectiveness 46

$\begin{array}{ll}\text { Summary } & 46\end{array}$ 
Introduction

Exploration of evaluation methodologies

Study design

Recruitment of interviewees

Rigor / quality 53

Ethical considerations

Summary

The interviews

Psychiatric Emergency experience of participants

Strengths of the Psychiatric Emergency Care Centre Service

Weaknesses of the Psychiatric Emergency Care Centre Service 
Role clarity and challenges

$\begin{array}{ll}\text { Quality and service development } & 93\end{array}$

$\begin{array}{ll}\text { Methodological reflections } & 96\end{array}$

$\begin{array}{ll}\text { Implications and recommendations } & 97\end{array}$

$\begin{array}{lr}\text { APPENDICES } & 98\end{array}$

Appendix 1: Example of framework to review literature used in the $\begin{array}{ll}\text { evaluation } & 98\end{array}$

Appendix 2: Participation Information Form 99

Appendix 3: Consent Form 102

Appendix 4: Revocation of Consent Form 103

Appendix 5: PECC Nurses Interview Schedule 104

Appendix 6: ED Nurse Interview Schedule 107

Appendix 7: Consumer Representative Interview Schedule 108

Appendix 8: Director of St Vincent's Mental Health Services Ethics

$\begin{array}{lr}\text { Approval } & 109\end{array}$

Appendix 9: St Vincent's Human Research Ethics Committee Approval 111 


\section{List of Tables}

Table 1: Triage Categories used in Mental Health

Table 2: Mental Health ED Presentations and PECC Admissions 2005-20008

\section{List of Figures}

Figure 1: Algorithm for PECC Admissions

Figure 2: Total Mental Health patients Admitted to PECC 2005-2008

Figure 3: Total Females and Age Admitted to PECC 2005-2008

Figure 4: Total Males and Ages Admitted to PECC 2005-2008 


\section{Chapter 1: Introduction}

Up until the 1970s and 1980s people with diagnoses of mental illness were nursed in large psychiatric institutions. The onus was on care and confinement and mental illness was treated largely with psychotropic medications. With the move from hospital to community, emergency departments (EDs) have become frequent entry points to mental health care. In some areas EDs are the preferred point of contact for all acute mental health assessments and treatment. As a result of these developments, in July 2005 the New South Wales (NSW) government introduced the formulation of nine Psychiatric Emergency Care Centres (PECCs) across New South Wales.

The introduction of PECC services was designed for the larger metropolitan hospitals as part of the broader Mental Health Emergency Care Program (NSW Health, 2007) to address the increasing numbers of referrals for consultation and assessment. PECCs are assessment and treatment units that include short stay bed facilities co-located in EDs whereby mental health specialists and clinicians provide 24 hour assessment and care.

Different site specific models of care have been adopted in EDs and PECCs throughout Australia but little research has been done on the effectiveness of care within these units. This thesis presents the findings from an evaluation of one PECC service, the St Vincent's Hospital PECC service which opened in November, 2005.

\section{Background}

In 2006 the NSW government invested \$5.8 million to establish PECC units in major metropolitan hospitals (NSW Department of Health, 2006) as part of wider plans to change and strengthen existing mental health services. The implementation of PECC services was one of several strategies to improve and integrate mental health services to meet the demands of consumer care. Nine PECC units are currently operating, one of which is located at St Vincents. St Vincent's operational budget of approximately $\$ 1.5$ 
million is funded by NSW Health (B. Hudson, personal communication, February 6, 2009).

Each PECC unit operates autonomously and their goals are to include rapid access to specialised care and assessment in meeting the local needs. However, service provision between units is governed by an Area Health Service. While St Vincent's Hospital is within the South Eastern Sydney Illawarra Area Health Service (SESIAHS), its relationship with the area is seen as a partnership. The St Vincent's PECC is one of three in the SESIAHS region and is expected to share the load of brief admission and assessment presentations.

St Vincent's PECC service is located in Sydney. It is a nurse-led unit which is co-located in the emergency department. It sits on a service continuum which aims to avoid unnecessary hospital admission and/or premature discharge into the community. The PECC is one of several mental health services provided by St Vincent's hospital responsible for the provision of mental health care to the residents of the inner city of Sydney. The residential population is approximately 110,000 and covers a 16 square kilometre area (St Vincents, 2008b). However, due to the exceptionally large volume of patients with mental health problems presenting to St Vincent's ED the local demand appears to exceed area wide needs (B. Hudson, personal communication, February 6, 2009).

Apart from the work of Frank, Fawcett and Emmerson (2005) little is written about PECC services. Frank et al. completed a descriptive study of the first Australian psychiatric centre and found that the co-location of ED and psychiatric emergency centre (PEC) provided several positive outcomes for services and patients. They include improved clinical care for patients; direct access to specialised mental health staff; taking early responsibility for patients and reduced access block. Given that so little is known about PECC services attention was also given to describing the service in considerable detail so that others could establish such a service more easily. As the St Vincent's PECC service is nurse-led, a key aspect of the current study was on PECC nurses' service delivery and 
their contribution to PECC service outcomes. The study was therefore designed to learn more about how nurses' work in psychiatric emergency care and what is it that they do that makes a difference to patients' care and the provision of psychiatric emergency care generally.

\section{The study}

The objectives of this study were:

- $\quad$ To describe the service development, organisation and model of care;

- $\quad$ To describe who and why people use the service;

- To describe the PECC nurses activities and responsibilities including the benefits, challenges and difficulties of delivering this model of care;

- $\quad$ To assess the effectiveness of the PECC nurse role from the nurses and consumers perspective;

- To assess nurses and consumers views on the appropriateness and acceptability of the service; and

- $\quad$ To identify what works well and what needs to change to ensure the service provides best practice.

It was anticipated that by addressing the above objectives issues would surface and the report would feed back results to key stakeholders (clients, the organisation and staff). The potential to improve the quality of the service and inform service development was the principle underpinning this study.

\section{Overview of the research}

Evaluation research was the methodology selected to describe the St Vincent's model of care and to assess the effectiveness of the service. The development of this evaluation involved an agreement from senior clinicians including NSW St Vincent's Hospital Population Health, Mental Health Services and Emergency Department Directors and the 
Victoria University of Wellington Graduate School of Nursing, Midwifery and Health New Zealand.

Good professional practice is dependent on informed decision making that makes explicit the expected outcomes, standards and intentions of health care interventions, and the purpose of evaluation research is to provide practical information to support practice (Clarke, 2001; Trochim, 2006). According to Walsh, Duke, Foureur and McDonald (2007) the three main purposes of evaluation are to i) formatively assess with the aim of identifying potential issues at a formative stage; ii) describe what takes place though process evaluation that attempts to understand strengths and weaknesses; and iii) investigate achievement and effectiveness to allow stakeholders to ascertain contribution, consequences and future needs through impact or outcome evaluation. The evaluation covered the period from November 2005 when St Vincent's PECC opened to December 2008. Data gathering for the evaluation commenced in April 2008 and was completed in May 2009. Three sources of data were used organisational documents, existing patient data on utilisation and interviews with PECC and ED nurses and with a consumer representative.

\section{Introduction to the researcher}

As a Māori (people of the land, indigenous people of New Zealand) nurse from Gisborne, a rural city on the East Coast of New Zealand (NZ) my interest in psychiatric emergency care began 1998 when I made a career change from theatre nursing to mental health nursing. My interest began during a student placement in an intensive care unit (ICU) where I observed a member of the psychiatric assessment team advocating for a patient who had history of suicide attempts and self harm behaviours. The patient's complex mental health history meant co- management in the ICU would be better for the patient than being in a psychiatric unit. I recall being fascinated by the differences in perceptions, language and behaviour, the two groups had when dealing with the patient. The experience had made such an impact I sought opportunities to work in areas of crisis and emergency assessment and intervention. 
My mental health nursing career followed a pathway through three areas. Firstly, I joined the dynamic Ngati Porou Hauora Mental Health Team, on the East Coast, NZ as a nurse key-worker then joined Tairawhiti Mental Health and Addiction Services and worked with a management team of forward thinkers and nurses who were unafraid to try new innovations of care despite limited resources and financial constraints. Finally, I was a lecturer for the Universal College of Learning Nursing School, Gisborne, New Zealand. The students shared their struggles to make sense of issues pertaining to mental health, their stories of successes and losses and about their families. I believe that a person who acquires knowledge should share it with others so that it benefits the wider community.

I commenced working at St Vincent's PECC in July 2006 and hold the title Clinical Nurse Specialist. I first became aware of PECCs when researching for information about mental health and primary health services. I found an article describing a new frontier for mental health nursing (University of Technology Sydney, 2003). The article highlighted problems in the delivery of emergency mental health care experienced in Australia and the United Kingdom. Hudson, a Clinical Nurse Consultant stated in the article that the integration of mental health nurses within emergency care teams would be one solution toward an improved provision of care. He described a new model and framework of psychiatric emergency care which was introduced for nursing teams and has contributed to St Vincent's ED reputation as one of the safest for patients and staff in Sydney. Within six months of reading the article I joined St Vincent's PECC team.

The transition from Gisborne to Sydney was dynamic in terms of people, volume of noise, movement, massive buildings and cafes everywhere. It is a city of diversity in cultures, of people, languages, arts and theatres. I was excited by the challenges of the unknown that lay ahead and what the city had to offer. However, my excitement turned to fear on the first day at work. The ED was busy with people in stretchers attended by ambulance personnel, police with patients in handcuffs waiting for an assessment by the psychiatric emergency team, teams of doctors and nurses attending to patients, alarms screeching in the background and numerous people in the triage area and waiting room. These were scenes I have seen in movies and television. In time I overcame my fears 
when I realised that PECC although a nurse-led service, is supported by a multidisciplinary team and no nurse works in isolation.

As a nurse working in Australia I recognise similarities in how mainstreaming of mental health services into the general health care system, deinstitutionalisation and insufficient community based mental health services have impacted on secondary services. It has led to an increased attendance to emergency departments or inappropriate services by those who have mental health problems. While my experience in NZ emergency mental health care has been in community mobile teams, McClintock and Ihimaera (2007) claim there is a diminishing workforce and lack of appropriate training for preparing crisis workers to work in the ED environment. In an effort to bridge these concerns I believe mental health nurses, especially those who work with emergency cases have a commitment to ensure their clinical practice includes skills that support patients who present to ED. The implications are that the increasing trend of presentations to the EDs will no doubt influence the role of ED staff to include mental health emergencies.

\section{An overview of PECC services}

PECCs provide care to patients 24 hours a day, 7 days a week. They are a small inpatient unit allowing for observation, assessment and short term care. Although PECCs have developed over several years in North America, little is known about the effectiveness of the model or how it works to deliver services. According to Frank et al. (2005) the first Australian PECC commenced in 1983 in Queensland. Their report describes the operational status of the model highlighting service delivery and effective relationship between PECC and ED.

As will be shown in Chapter 4 which presents a detailed picture of the St Vincent's service, the PECC provides continuing assessment treatment over 48-72 hours by nurses who are led by a Clinical Nurse Consultant and supported by a multidisciplinary team. The core aim of service delivery is that emergency psychiatric care will be delivered by experienced health professionals, efficiently, effectively, ensuring patient safety and 
privacy in a culturally sensitive manner. Since its development the PECC organisational structure has changed, nursing roles redefined to include a full time ED liaison position rotated by PECC nurses and the recognition of PECC as a nurse-led service.

While PECC services have existed at St Vincents since November 2005, no formal evaluation of the service has been done to date. This study will therefore provide important information for the St Vincent's PECC service. The evaluation will also contribute generally to what is understood about PECC services, about the nursing work in these services, and may address some of the issues and concerns that have been raised by the PECC model.

\section{Thesis overview}

This thesis, which represents a personal journey of discovery as well as an evaluation of St Vincent's PECC service, is presented in six chapters. This first chapter has an introduction to the research question, the setting in which this research took place and to myself as researcher. My journey to a PECC unit is outlined in this chapter along with an explanation of the service and why it was implemented. Evaluation of the service became a natural progression of my journey and therefore the research journey and process is outlined.

Chapter 2 presents the literature on models of emergency psychiatric care from the last decade with a particular focus on Australia. While there is increasing research on mental health as services seek to find the most effective way to deal with mental health issues this chapter reveals the dearth of information in the field of PECC services. The literature review establishes what was already known about psychiatric emergency services.

Chapter 3 describes in more depth the St Vincent's PECC service aligned with national and local documents of relevance. Within this chapter my perspectives of the roles of nurses who work in PECC and ED liaison are outlined along with discussion of mental 
health presentations to ED and admission to PECC. The model of care developed within St Vincent's PECC is explained including the cross sector relationships that needed to be developed for successful implementation.

Chapter 4 outlines evaluation research as a methodology, it expands on process-impact evaluation as a means of developing research enquiry for data collection and data analysis. Ethical considerations, as well as rigour and quality are discussed.

Chapter 5 contains findings of this study. Responses from individual face-to-face interviews and written responses are used to describe strengths and weaknesses of the service. The different perspectives tell the story of what works well and what can be improved with the intent to improve ongoing care. Alongside personal perspectives analysis of local, national mental health and St Vincent's mental health documents are used as a means of comparison and collaboration to develop key themes. Documents provide an accessible picture of the PECC service that legitimates subjective data.

Chapter 6 concludes the thesis with a discussion on this in-depth picture of a psychiatric emergency care centre. The intent in this chapter is to highlight strengths and weaknesses and make recommendations for clinical practice, education and further research. The discussion returns to the themes identified. 


\section{Chapter 2: Literature Review}

\section{Introduction}

A literature review was undertaken to identify current psychiatric emergency care models involving nurses utilised in emergency departments. The review of the literature mainly covered the models of care which are utilised in many hospital emergency departments in Australia. The aim of the review was to gain a better understanding of psychiatric emergency care models, to identify the nursing models of psychiatric care, and to ascertain how these models were evaluated to measure effective care. This review largely focuses on research articles published between 1997 and 2008 to reflect the timing of implementation of the St Vincent's hospital psychiatric emergency care centre (PECC) service situated in Sydney, New South Wales (NSW). Historical literature related to the development of psychiatric emergency care in the emergency department is also highlighted. Particular attention was made while undertaking the review to highlight any research set in Australia.

\section{Search Strategy}

Psychiatric emergency care models were identified by performing a Medline, Cumulative Index of Nursing and Allied Health Literature (CINAHL) and PsychINFO search using keywords and phrases: psychiatric emergency care, mental health nursing, nursing models of care, consultation liaison, mental health nursing, triage, emergency departments and crisis services. A manual search was also performed, from appropriate references of publications retrieved and from the Journal of Psychiatric and Mental Health Nursing and International Journal of Mental Health Nursing.

This chapter presents the findings that were extracted from the literature using a standardised format, referred to as the 'framework', to describe what is known about each of the models. The framework involved the creation of tables to systematically summarise findings from the literature. Appendix 1 presents two examples of how the findings were extracted from papers. Firstly, this framework was designed to capture where the model is 
located in the full emergency department (ED) setting and the assumptions/premises on which the model is based. Secondly, it was used to capture how care is generally organised, that is, what is the patient journey from arrival at ED, triage, treatment, and discharge through to follow up. This includes what is known about how the mental health and ED staff interacted. Thirdly, the framework was used to establish who works in the model including what is known about the particular roles, qualifications, skills and knowledge of the staff. The fourth aspect of the framework captured what is known about the effectiveness, and the issues about the workings of any of the models. In analysing the literature key areas were looked for, such as the role and structure of the nurses' work and the evaluation processes utilised.

\section{Overview of the literature}

The search revealed a considerable volume of literature on psychiatric consultation liaison nursing but a smaller volume on mental health liaison nursing. The literature revealed three main models of psychiatric emergency care. These are the consultation liaison (CL) model, the mental health nurse (MHN) in ED model and the psychiatric emergency care centre (PECC) model. Each of these models is currently practised in Australia and has been previously identified (Frank et al. 2005) as the key models. In looking at the literature it was clear that triage is beginning to surface as a specific model but there is a paucity of established local or international body of knowledge to support triage as a model of care. Therefore this has been excluded from this literature search as the focus is on psychiatric emergency care performed by mental health professionals.

The literature revealed that there were significantly more studies centred on the consultation and liaison model both nationally and internationally. The literature on the mental health nurse in the emergency department was quite extensive as it has featured since the 1960s, more specifically in relation to the setting up of the service rather than evaluation of the role. Only one paper on PECCs in Australia (Frank et al. 2005) emerged although another paper (Wand \& White, 2007) provided useful background information regarding the development of PECCs in NSW. As a consequence the majority of information reported in this chapter on PECCs was accessed from NSW Health and 
PECC service documents. It is important to note that in the articles a discussion on cost effectiveness was notably absent. The majority of the papers had a clinical focus and a number of articles presented service descriptions with a view to expanding services. Many articles were written in the early phase of the services developing therefore had limited evidence of effectiveness.

\section{Overview of Psychiatric Emergency Care Services in Emergency Department}

The literature shows that different psychiatric/mental health services have introduced different models of care to assist ED staff with mental health presentations. Each model consultation liaison (CL), mental health nursing (MHN) and Psychiatric Emergency Care Services (PECCs) are site specific and have adapted service provision to meet local needs. For example, there are PECCs that have virtual beds (ED beds utilised by mental health services and funding arrangements are site specific) in the ED and others with designated real beds.

The CL role originated in the United States of America (USA) in the 1960s and included consultation and education to general hospital nurses and medical staff (Callaghan, Eales, Coats, \& Bowers, 2003). These nurses were considered as clinical specialists who mainly worked in the management of patients with a primary medical condition and co-morbid mental health problem that influences the provision of medical care (Bryant, Foster, McNamara, \& Sharrock, 2007; Callaghan, Eales, Leigh, Smith, \& Nichols, 2001; Thompson, 2005; Wand, 2004). During the 1970s the role expanded to include direct care of people with mental health problems in emergency department as well as education and liaison with other health professionals (Thompson). The trend for designated mental health nurses in emergency departments began in North America in the 1990s (Wand \& White, 2007). There is evidence to suggest that MHN role evolved in response to the increasing mental health presentations to ED. To meet the health needs and demands of this group some mental health services in Australia have introduced mental health nurse consultants in ED (Sharrock, Bryant, McNamara, Forster, \& Happell, 2008). In addition, growing support for mental health nurse practitioner to be introduced in EDs has emerged (Wand \& Fisher, 2006; Wand \& White, 2007). 
Although psychiatric emergency care centres in ED have existed for many years in North America there are significant differences in delivery of care, organisation and structure of these services (Currier \& Allen, 2003; Wand \& White, 2007). However, psychiatric emergency care centre development in Australia is more recent with nine being established in a number of sites in NSW since the first PECC unit in Queensland.

\section{Consultation Liaison Model of Care}

The Consultation Liaison model is widely reported in the literature, and is described as the most common model of psychiatric care for patients who present to emergency departments in Australia (Frank et al. 2005). The consultation liaison role was able to be filled by nurses when it was acknowledged that mental health nurses were as competent as medical professionals to complete assessment in the emergency area and would also reduce junior doctors' roles (Beech, Parry, \& Valiani, 2000; McEvoy 1998; Thompson, 2005). Patients are the responsibility of ED staff until such time they are referred on to other services.

\section{Historical background}

The development of the role of the mental health or psychiatric CL nurse in the emergency department was partly prompted by the recognition of psychiatric nursing as a specialty and increasing awareness within nursing groups of the relationship between psychosocial needs and physical health of the patient (Bryant et al. 2007; Minarik \& Neese, 2002). These original mental health CL nurses worked alongside general nurses as consultants across a variety of settings (Roberts, 1997; Wand, 2004). However, whilst the role focused on consultation, advice and education the CL nurses did not at this stage, have direct contact with patients (Brendon \& Reet, 2000; Roberts \& Whitehead, 2002; Sharrock \& Happell, 2000).

By the mid 1970s the mental health CL role had moved towards more direct interventions with patients in EDs. It involved education of the ED nursing and medical team, and liaison between various health professionals (Roberts, 1997; Thompson, 2005). Also, 
significant changes in nursing practice were occurring which strengthened CL nursing as a specialist group. These changes involved the introduction of new practice models, increased collaboration with other health professionals and working across professional boundaries, inclusion of clinical supervision and the introduction of educational programs to prepare nurses at the masters' level (Roberts, 1997; Roberts \& Whitehead, 2002).

In the United Kingdom (UK) the CL role originated from crisis intervention services based in accident and emergency departments however, unlike United States of America (USA) it is not recognised as a specialist or subspecialist area of practice. The role evolved in response to the increasing deliberate self harm and suicide presentations to the emergency department. These mental health CL nurses conducted assessments, brief therapeutic interventions and liaised with psychiatrists where necessary.

\section{Aims of the consultation liaison model of care}

The model is based on the premise that emergency care for many people in psychiatric crises is best provided by a mental health specialist in consultation with the emergency staff. There are various terms used to describe the consultation liaison model, many of which describe the role of the nurse. These terms include mental health consultation liaison nursing, psychiatric consultation liaison nursing and consultation liaison nursing (Roberts, 1997; Sharrock et al., 2006; Wand, 2004). Debate regarding the ideal terminology that describes this group of nurses remains a subject of contention.

The Australian College of Mental Health Nurses Consultation Liaison Special Interest Group (Bryant et al. 2007) concludes consultation-liaison is the most appropriate term and expects further debate as the group develops. While there has been much debate about the most appropriate term for this role it is dependent on which school of practice and education the practitioner affiliates to rather than actual role (Bryant et al.). Bryant et al. assert that the debate centres on the use of the term mental health and whether skills obtained through psychiatric nursing education are compromised allowing more generic 
terms to be applied to a less specialist body of knowledge for use by a range of practitioners.

The consultation liaison model of practice may vary from service to service and CL nurses can be based in community settings, inpatient units, general hospital settings or emergency departments. Changes within the consultation liaison model has led to a gradual expansion of the CL role from one centred on individual patient care to now include the provision of specialist mental health care over a variety services (Regaisis, 2005). Sharrock (2006) acknowledges that earlier works in the development of the specialist roles were instrumental in the development of similar specialties of mental health nursing in other countries.

\section{The role of the consultation liaison nurse}

The literature shows that the person in this role is involved with assessment, and assists general nurses to develop a plan of care for those who have mental health issues. While only a few authors identify any direct involvement with triage (Bryant et al. 2007; Happell, Summers, \& Pinikahana, 2002; Smart, Pollard, \& Wagpole 1999; Thompson, 2005 ) it is more frequently noted that the consultation liaison nurse role is important in the triage process where presentation occurs under requirements of the Mental Health Act. Wand (2004) indicated in his survey that mental health liaison nurses were accessible for assessments and management of patients who present to ED. In both aspects a key role for this position is created to improve breakdown in communication and improved relationships (Bryant et al.; Happell et al.; Smart et al; Thompson).

Liaison between acute and mental health services with other services external to the hospital for continuum of care once the patient has been discharged are important features of the role (Bryant et al. 2007). Another important aspect of this role is consultation (Wand \& Fisher, 2006) which is the provision of consultation to staff and direct specialised psychological care to patients and their families (Roberts, 1997). In the UK West Middlesex University hospital service the mental health liaison nurses were based in 
the accident and emergency department (A\&E) and work parallel to, but independent of, the existing consultant psychiatrist. Additional functions of the team included teaching staff within the hospital about mental health problems and medico legal issues, provision of clinical supervision, liaising with other health providers and collection and analysis of patient data (Brendon \& Reet, 2000).

Most literature indicates that a high educational role is fundamental to this role in particular areas such as alcohol and drug and legal aspects (Bryant et al. 2007; Ryan, Clemmett, \& Snelson, 1997; Sharrock \& Happell, 2006; Thompson, 2005). Additional benefits are the role model that allows ED nurses to grow in confidence alongside the role of the consultation liaison nurse (Thompson).

These nurses can also be involved in developing and reviewing policy and processes at an organisational level. This involves consulting to the broader organisation projects and policy development around mental health services (Sharrock \& Happell, 2006). A feature of this position is that the person is often not employed solely in the emergency department and therefore comes with a fresh perspective (Happell \& Sharrock, 2002; Thompson, 2005). This allows for collaboration across different specialties (Ford, 1998) and a wider range of treatment options.

\section{Effectiveness of consultation liaison model}

The evidence shows that mental health nurses were as effective in completing mental health assessments as psychiatrists and the role assisted with reducing junior doctor workloads (Beech et al. 2000; Roberts, 1997; Thompson, 2005). Nurses are considered effective working in role to the extent that one mental health service responded to junior doctors working excessively long hours by a establishing the mental health liaison nurse service at West Middlesex University hospital to reduce some of the call on the doctors (Brendon \& Reet, 2000). 
Effectiveness is often measured by the ability to improve services in accordance to strategic documents. Brendon and Reet (2000) note that driving the development of the service was the release of UK National Health documents such as the Calman Report 1993 which reported increased suicide rates and made recommendations to reduce them, including provision of psychosocial assessments by specialists for people who have harmed themselves. Another model of the mental health liaison team in the UK involved a multidisciplinary team including mental health nurses, psychiatrists and social workers (Webster \& Harrison, 2004) proposes more research is needed to endorse the effectiveness of this approach.

The literature concentrates on presentation or referral rates or patient characteristics rather than evaluation or description of services offered (Wand, 2004). Much of the literature around the consultative liaison role is descriptive accounts of successful operation with few actual evaluations of the service (Sinclair, Hunter, Hagan, Nelson, \& Hunt, 2006). Wand (2004) and McDonough et al. (2004) undertook some evaluations but provided insufficient objective data related to the benefits of the service to patients.

Within the literature, the themes related to effectiveness of this role relate to the benefits of early intervention in people with complex needs and those who self harm (Brendon \& Reet, 2000; McDonough et al. 2004; Ryan et al., 1997) and reduced waiting times of patients seen in A\&E department (Wand, 2004). Having knowledge about the local patients and the ability to utilise other appropriate services helps ensure a continuum of care (Brendon \& Reet) that is beneficial for all concerned. Another essential point was the recognition of the mental health liaison nurses as experts by their medical and nursing colleagues and that patients were more effectively managed (Brendon \& Reet; Sinclair et al. 2006; Wand).

\section{Issues with the consultation liaison model}

Contradictions in the literature regarding the benefits of the CL model are evident. Some argue there is no evidence of reduced waiting times (Frank et al. 2005; Sinclair et al. 
(2006) and others report decreased waiting times in ED (Thompson, 2006; Wand, 2004). Another problem with the model is that sometimes it is not popular with the ED team who find that there are often long delays before the person is assessed or accepted as the consultation liaison person is not always on site (Frank et al.; McArthur \& Montgomery, 2004). Concern has also been raised that mental health accepts responsibility only when a bed becomes available or the person can be discharged to community care and therefore the patient remains the responsibility of the emergency department (Frank et al.).

\section{Mental Health Nurse in ED}

In this model mental health nurses are based in emergency departments 24 hours per day, and 7 days per week (Frank et al. 2005; Wand \& White, 2007). These mental health nurses are often called mental health liaison nurses and their arrival occurred in response to the increasing number of people with mental health problems accessing emergency department services. Patient care remains with ED staff until a bed can be accessed or the person discharged to community services,

\section{Historical background}

The emergence of the mental health nurse in ED was in response to deinstitutionalisation, mainstreaming of services and insufficient community-based mental health resources (McClintock \& Ihimaera, 2007). While this trend began in North America in the mid 1990s the issues mentioned above have now resulted in this model being an integral part of services in many countries (Wand \& White, 2007). Accordingly, there has been considerable literature, which supports this initiative, from many western countries (Beech, Parry, \& Valiani 2000; Brendon \& Reet, 2000; Callaghan et al. 2001; Clarke et al. 2005; Hughes \& Clarke, 2002; McDonough et al. 2004; Morgan \& Colman, 2000; Sinclair et al. 2006; Wand, 2004; Wand \& White). 


\section{Aims of the mental health nurse in the ED model}

The chief aim of this model is to provide rapid assessment, reduce patient waiting times and stop patients leaving without being seen by medical and mental health teams (McDonough et al. 2004; Wand \& Schaecken, 2006). This means that the nurse is an expert consultant and within this model a key component is to better inform and support non mental health colleagues in regard to their concerns regarding patients with mental health need and thus reduce stigma (Gillette et al. 1996; Wand \& White, 2007). A further aim is to provide an early direct link between mental health and community and primary health services.

\section{The role of the mental health nurse in emergency department}

The literature surrounding the roles of mental health nurses in emergency departments differs according to country of origin. In both the UK and Australia the role is more likely to be at an advanced level whereas the USA is more likely at a specialist position (Karshmer, 1997). In Australia a concerted effort was made by the government to fund nurse consultants to these positions. Wand (2004) identified that this initiative commenced in 2000 when funding was provided for these positions across New South Wales. There is a dearth of information directly related to the role which varies dependent on the particular environment in which the position was established. This makes being specific about aspects of the role complex.

Where this role is at a nurse consultancy or practitioner level the role includes advanced practice role modelling, professional leadership, practice development research and evaluation (Cox, 2000; Hayes \& Harrison, 2003). In countries where the role is at a lower level the nurse may not have advanced skills and therefore does not fulfil consultancy, policy development and prescribing tasks. In these countries the skills offered are rather an extension of generic mental health nursing skills applied in an emergency setting (Roberts, 1997, 2002). Generally the role of mental health nurses based in the ED includes the assessment and management of patients who present with mainly mental health problems and ensures that they have equity of access to medical treatment (Wand, 2004). 
The literature show that the overriding principles of this type of service include: triage, medical assessment, mental health assessment skills, therapeutic skills and care coordination; other activities involve the provision of education, clinical governance of staff, participating in health promotion, role modelling and leadership. Furthermore, that the mental health nurse maintain regular communication with other services to ensure effective access of care to patients and their families.

\section{Effectiveness of mental health nurse in ED}

Wand (2004) evaluated the MHLN service over the first two years and suggests that the MHLN role has significant benefits for patients presenting to emergency of care by reducing waiting times, streamlining transition through the department and improving follow up. Wand and Schaecken (2006) evaluated the mental health liaison service in an ED in Australia and found that consumer feedback was promising; consumers reported that they were treated with respect with good discussion around discharge follow up and decision making. However, this feedback related to only one hospital and also showed there remained room for improvement.

Other evaluations of MHLN services have shown considerable levels of approval from both staff and patients (Wand \& White, 2007). A further evaluation by Eales, Callaghan and Johnson (2006) in an individual setting in the UK concluded that the service with a dedicated mental health nurse offers a more detailed lengthy and specialist service. However, once again this finding is limited to one context and is inconclusive. McDonough et al. (2004), Wand (2004), Clarke et al. (2005) and Wand and Schaecken (2006) found that this role meant reduced waiting times for access to specialist care, management and follow up care. In contrast an investigation related to the effectiveness of this role by Sinclair et al. (2006) found little impact on waiting times or patient satisfaction. Wand and White (2007) maintain MHLN is the only model that is cost effective as it can be transported to most EDs. 
Currently in Australia there is wide support for the introduction of mental health nurse nurses practitioners (NP) in ED (Clinton \& Hazelton, 2000; Wand \& Fisher, 2006). NPs are registered nurses who have extensive expertise in their chosen specialty and who have attained a masters or higher degree in nursing. Wand and White (2007) claim NPs were introduced to complement and improve services and health care outcomes for patients under their care. Wand and Fisher's description of the mental health NP role based in an Australian ED, attributes success of the role to; transparency of consultation and evaluation processes in the development of the service, partnership of disciplines and clinical services and maintaining a nursing focus rather than duplicating psychiatric medicine.

\section{Issues with the mental health nurse in ED model}

Frank et al. (2005) claim that this model is more expensive than the consultation liaison model and is therefore usually only seen in medium to large hospitals. Again the mental health services do not take early responsibility for the patient and this depends on availability of bed state or community services and therefore blocks bed flow in EDs (Frank et al.; Wand \& White 2007). While there is a significant amount of literature on this model, on examination the value of this model is unclear with insufficient effective evaluation.

\section{Psychiatric Emergency Care Centre Model of Care}

The psychiatric emergency centre (PECC) within ED providing care 24 hour a day, 7 days a week. It is a small inpatient unit allowing for observation, assessment and short term (24-48 hour) care. Patients are the responsibility of mental health services.

\section{Psychiatric Emergency Centres - historical background}

Frank et al. (2005) reported that the first PECC service commenced in one of the busiest emergency departments in Queensland, and that assessments increased from 440 in 1994 to 7200 in 2004 . They predicted these numbers would increase by $15 \%$ per year. 


\section{Aims of the PECC model}

PECCs aim to improve the quality of clinical care for patients experiencing mental health problems who present to the ED and to reduce delays in access to specialist care and to develop a sustainable service model for ED care (NSW Health, 2007). The limited literature surrounding PECCs suggests that there is considerable variation in both organisation and structure in services; however, most are identified as autonomous services that parallel care with emergency departments (Currier \& Allen, 2003; Wand \& White, 2007). Mental health services accept responsibility for patients on entry to the emergency department and therefore aim to provide rapid assessment in a timely fashion and ensure assessment occurs before there is time for the patient to leave.

\section{The role of the PECC nurse in emergency department}

There is a lack of research and literature around the role of the PECC nurse however Frank et al. (2005) identified key areas of partnerships with various services, including emergency department, hospital security service, alcohol and drug service, child and youth mental health service, police and ambulance. PECC nurses' responsibilities include triage and assessment by phone or on arrival in the emergency department; mental health, alcohol and drug, risk assessments, short term inpatient care for up to 48 hours and referral, provision of access to other specialist services and resource information (Frank et al.). Similar to the consultation liaison nurse role, more advanced nurse practices such as prescribing do occur although this varies across services. PECC nurses provide a significant enhancement of consultation liaison services in the ED as well as designated inpatient services (NSW Health, 2007).

Another important function is bed management of acute inpatient mental health beds to ensure bed management flow to prevent bed access block in ED. There is a high level of networking with other bed managers, senior medical staff and agencies involved in the negotiating, planning and coordinating of a patient's transfer to or from another mental health facility. Although this role too may vary across sites as there are designated bed managers in some hospitals. 


\section{The role of the PECC nurse in the PECC unit}

There are two roles which PECC nurses rotate on a daily basis. One nurse assumes the incharge role however, both nurse share the work load and patient ratio. That means each nurse is responsible for their own patients. A comprehensive description of the two roles is provided in Chapter 3. The role of the PECC nurse in the unit is involved in the management and caring for patients who need a brief admission and access to specialist care. The PECC nurse is pivotal in supporting the liaison nurse in ED in areas of bed coordination and patient flow, admissions and discharges and ensuring patients are linked to appropriate services. Another important role is the preceptorship of student nurses and orientation of new staff. Furthermore, PECC nurses prepare and escort patients on transfer to other hospitals. PECC nurses rely on the bed manager to negotiate beds from other health areas especially in cases of patients who need longer care. Every effort is made to find the patient an inpatient closest to their home or family.

\section{Effectiveness of the PECC nurse}

Frank et al. (2005) state that this model is highly acceptable to ED staff as the mental team accepts responsibility for patients early. Other benefits include direct access to specialised mental health care, ambulance and police services, no access bed blocks, reduced waiting times and better quality of care. Frank et al. suggest that as this is a designated unit the person's privacy, confidentiality and respect are more easily maintained and are likely to be more sensitive to their needs. The units allow short term intensive assessment and monitoring of patients which thus reduces risk of self harm and absconding. This means the need to a formal inpatient admission is reduced.

The NSW Health (2007) report described the first 12 months of seven PECCs. Each service was evaluated using clinical data collections, surveys of PECC consumers and carers, surveys of PECC and ED staff, clinical file review and facility audits. Data were collected on 8,222 presentations from February 2006 to February 2007. The data reported:

- $\quad$ Most presentations happened after 5pm and peaked in the evenings; 
- Majority of PECC duties were assessment in and consultation to the ED;

- $\quad$ Approximately $16 \%$ of ED contacts were admitted to PECC units;

- $\quad$ Almost half of PECC contacts were patients brought in by police or ambulance;

- $\quad 39 \%$ self presented and common problems were overdose or self harm (38\%), psychotic symptoms (27\%) and depressed mood (25\%);

- $\quad$ Post assessment the most common diagnoses were mood disorders (27\%), psychoses (25\%) and substance abuse disorder (18\%); and

- $\quad$ Around half of PECC admissions were discharged after care while half were transferred to other mental health inpatient units.

The results of the evaluation provided evidence of the positive influences PECCs have on quality of care, improvement to patient flow and reducing delay in accessing mental health care in the ED. In addition, the PECC service model has been delivered as planned and staff reported high levels of satisfaction with the model and occupational satisfaction. PECCs were described as safe environments where aggressive incidents are rare and the rate of patients absconding was reduced (NSW Health, 2007).

\section{Issues with the PECC model}

While many people are responding positively to PECCs they are also perceived as another way of stigmatising people and not in keeping with integrated system (Mendoza, 2006; NSW Health, 2006). Some writers are also concerned that PECCs may divert funds from the community area (Mendoza; Wand \& White, (2006). Frank et al. (2005) claim that PECCs are more appropriate for large EDs (>500 beds and with 3000 presentations per year) because they cost more than one million dollars per year to staff. Wand and White consider that these high costs and the need for a number of presentations limit the viability of PECC services in Australia. 


\section{Discussion}

The findings from the literature review concur with those of Brown (2005) who conducted a literature review on psychiatric emergency services. Brown argued that there were methodological limitations across all areas of the literature that many dimensions of psychiatric emergency services remained unexplored such as structural aspects of crisis residences or disaster response teams, and there was a lack of a research agenda. The range of articles explored examined providers, clients, and services, access, utilisation, evaluation, treatment, and continuity of care including outcomes of these services. In all studies the sample sizes have been small and not necessarily representative of typical service populations.

Brown (2005) proposes future research that could address aspects of service structure such as how psychiatric emergency services by different providers are comparable in organisation and content. Whether presentations in different geographical and clinical presentations are significant and how extensive the differences are in terms of impact on outcomes. Published research was found that developed and evaluated a psychiatric screening tool to use across emergency services.

Brown (2005) found that while few empirically based outcome studies exist within literature those that exist utilise a number of different outcome measures making crossstudy comparisons difficult. This is because of retrospective and lack of pre-existing outcome data plus lack of a standard tool. Development and testing of standardised outcome measures factors are associated with client satisfaction, inpatient service utilisation and variation in arrangements that influence patient and service outcomes need to be considered (Brown). An evaluative approach as a template for understanding of structure, process, and outcome dimensions of service would help to identify necessary changes and developments mental health emergency services (Brown).

While there is considerable information about the consultation and liaison model of care much of the literature is descriptive and framed up organisationally. There appears 
nationally and internationally to be overlaps between role descriptions, because of organisational differences it is difficult to clearly differentiate a specific role. Some have looked at the effectiveness of the role but this often described the service with the actual aim to expand the service or support existing processes rather than showing valid evaluative processes that could be replicated.

Mental health nurse liaison and ED mental health nurse model is relatively new in Australia so information is valuable in terms of workforce development options. The PECC nurse role has elements of both these models however this is dependent on where the nurse works. PECC nurses are located in large hospitals where the staff is working at expert levels as consultants, through to smaller services staffed by specialist mental health nurses to services away from the ED staffed by enrolled nurses. No studies are specific in what the PECC role is or should be, nor, are there clear description of the education level of each nurse. The assumption is that the roles will be the same as either of the other models.

There is little evidence in any of the models about nursing work and evidence that nurses actually provide a range of therapeutic interactions to patients and their families that would be expected in this environment. Therefore, more work to evaluate patient satisfaction and how the nurse affects this on a daily basis is required. The evidence shows that there is little known about the PECC service and how it operates. What is known is that St Vincent's PECC is a nurse-led service that consists of specialist mental health nurses who are supported by doctors', ED and multi disciplinary teams.

The term nurse-led clinics/services first appeared in nursing literature in the 1980s but this accelerated further, extending to a number of specialty services during the 1990s (Hatchett, 2003; Wand, White, \& Patching, 2008). Hatchett defines the nurse clinic as "a clinic where a nurse has his or her own case load" (p. 2). This definition suggests this involves enhanced autonomy for the role nurses play in admission and discharge from clinics, along with appropriate referral to other health-care colleagues. Wand and White (2007) advanced this concept by suggesting nurse-led clinics aimed for costs 
effectiveness, better integrated pathways of care, and reduced hospital stays. However, Wand et al. (2008) indicate that nurse-led clinics can be simply an extension of a medical service and that there has been lack of rigorous exploration or substantiation as to their value. Hatchett had previously argued that it was critical for nurse-led services to be perceived as a specialist, as well as a cost-effective healthcare alternative rather than a second rate service resulting from consequences of overworked medical colleagues. Unfortunately these services are not always adequately evaluated.

St Vincent's PECC is a nurse-service because the nurses' do all the coordination and liaison with other services and families, including preparation of care plans and therapeutic interventions (St Vincents, 2008a). More recently, the introduction of the bed management role has extended the PECC nurses' scope of practice which is a major factor in decision making and service provision at a local level. PECC nurses and their role are crucial in the provision of mental health care to patients who present to ED, provide access to specialist services and ensure that patients are assessed in a timely fashion.

\section{Conclusion}

There are three main models of psychiatric emergency care provided in Australian EDs. The first most utilised is the consultation model where Acute Care Teams or Consultation Liaison Services assess patients who present to the ED. The second is that of the mental health nurse in ED and the third is the PECC service. Most research to date has been on the first two of these models with PECC being a recent option. The models vary depending on where the nurses are located, what responsibilities they have of patient care and how they are valued by staff and patients. Little is known about these models from a nursing perspective and as mental health patients use ED these models of care will be utilised in a variety of settings. This research will address some of this gap in knowledge by focusing on one PECC service and gathering information from a nursing perspective. 


\section{Chapter 3: Description of the psychiatric emergency care service}

\section{Introduction}

This chapter presents an overview of the St Vincent's Hospital psychiatric emergency care centre (PECC). It describes the service and roles of nurses in the provision of care. It is written from my perspective as a nurse working in the service and from hospital and government documents which provide national strategic direction and policy in relation to mental health services. I begin this chapter with an outline of the national imperatives that underpins the development and current service provided by St Vincent's PECC services. I then describe the St Vincent's PECC service and model of care which are the focus of this evaluation.

\section{Background}

In 1992 Australian Health Ministers agreed to a National Mental Health Strategy as a way forward to the development of mental health reform from 1993 to 1998. The Strategy identified several core areas for change, which included the integration of mental health care with general health services in mainstream settings and decreasing institutional care by increasing community based care for those with mental health problems. In 1998, The Strategy was consolidated in the development of the Second National Mental Health Plan and again in 2003 with the endorsement by all health ministers of the National Mental Health Plan 2003-2008 (Australian Health Ministers, 2003).

In 2006 the New South Wales (NSW) government released a five year plan New South Wales: A New Direction For Mental Health to provide easier access to a wider range of services to the people of NSW. Funding was allocated for the development of several PECCs within Sydney to provide an effective integrated care system in response to the increasing mental health presentations to emergency departments (EDs). 


\section{Description of Psychiatric Emergency Care Centres}

PECCs are 4-6 bed facilities normally located in EDs for patients with mental health problems who may benefit short term intervention. Service provision includes priority access to appropriate services, assessment, treatment, crisis stabilisation and close observation of patients involving nurses and multidisciplinary teams (NSW Health, 2007). Patients awaiting transfer to an inpatient bed, or who require further psychiatric assessment and treatment from other services can be admitted into PECC to avoid the blocking of ED beds. Access to ED beds can be problematic in most hospitals and utilising PECC beds is one way of mental health patients avoiding lengthy waiting times to access services. Another essential point, by ensuring steady patient flow through triage into ED helps to reduce patient waiting time to be assessed and avoid patients leaving without being assessed or treated.

\section{Governance}

NSW PECCs were set up in response to the increasing presentations to EDs by people experiencing mental health problems. Emergency department and mental health service initiatives were developed to implement coordinated, effective and accessible mental health services (NSW Health, 2007). St Vincents is one of several mental health services that come under South Eastern Sydney Illawarra Area Health (SESIAH) responsible for corporate governance and accountability including legal, quality and policy directives issued by NSW Health (2006). SESIAH ensures that key performance indicators in EDs are met which includes bed management and patient flow coordination of mental health patients. However, the day-to-day management of mental health services is directed by St Vincent's Director of Mental Health Services.

The PECC is one of 10 services within St Vincent's mental health service. Other services include inpatient unit, community case management, older aged psychiatry, rehabilitation, consultation liaison, shared care, mental health and human immunodeficiency virus in primary care; crisis intake and day clinic; clinical research for disorders and programmes for early and prevention disorders. 


\section{St Vincent's Psychiatric Emergency Care Centre}

The PECC assessment and where necessary short stay service aims to meet the needs of patients with mental health problems who require brief inpatient care. Included are those who may have organic problems. The service provides access to mental and medical health specialist care between 24-48 hours that is designed to avoid both hospital admission and premature discharge into the community (St Vincents, 2008a). The service is staffed 24 hours a day by mental health registered and enrolled nurses supported by emergency, multi-specialty and disciplinary teams.

The aim of the service is that emergency psychiatric care will be delivered by skilled and knowledgeable health care professionals in an efficient and effective manner, while maintaining safety and protecting privacy in a culturally sensitive manner. Underpinning the philosophy of care is that the delivery is consistent with the values of St Vincents and Mater Health Sydney. The values of compassion, justice, human dignity, excellence, unity, mercy, hospitality and respect are at the core of the Code of Ethics and Behaviour (St Vincents, 2008b). The target group are adults aged 17 years to 65 years who live in the SESIAH sector.

\section{Physical environment}

The PECC is co-located in ED and consists of six bed cubicles, lounge, two interview rooms, unisex toilet and shower. Double curtains around each cubicle allow each patient to maintain some privacy. Each cubicle is fitted with emergency equipment such as oxygen, suction, intravenous tubing and fluid solutions. This equipment is kept in a locked cupboard above the patient's bed. The crash trolley containing a mobile defibrillator is located in the emergency medical unit adjacent to the nurses' station. The nurses' station is designed so that staff can observe patients through glass windows similar to a flight deck. Likewise the patients have ready access to staff.

The unit is under surveillance with cameras in areas such as the two assessment rooms and lounge to observe patients who are very unwell, suicidal or with unpredictable 
behaviour. The entry into the PECC is via electronic security card or staff access. The security personnel office is situated next to PECC and request for assistance is immediate. In such incidences, there is an understanding that security officers are under the direction of the clinical team. Nevertheless the security officers are not to be utilised for the monitoring of patients, without the presence of clinical team (St Vincents, 2008a).

\section{St Vincent's PECC Model of Care}

The uniqueness of the St Vincent's model is the combination of staff selectively chosen for their speciality experience and ability to maintain autonomous clinical practice. Under the former nursing framework there was little room for clinical development because of the additional tier of management roles. The original team consisted of one nurse unit manager who was responsible for the day-to-day management of PECC. Responsibilities included budget forecast, staff management, recruitment and retention of the workforce. The nurse unit manager was involved with organisational planning and meeting service strategies and deadlines.

Reporting to the nurse unit manager were two Clinical Nurse Consultants (CNCs) who were responsible for mental health clinical practice and education of nurses in PECC, ED and hospital wide. Although the allocation of roles was directed by the nurse unit manager, nursing practice was directed by the CNCs. There were seven Registered Nurses (RNs) and one Endorsed Enrolled Nurse (EEN). In late 2006 and early 2007 the nurse unit manager, one $\mathrm{CNC}$ and four RNs resigned to take career opportunities in other hospitals. Mid 2007 remaining staff assumed extra responsibilities to cover the work load until new staff was recruited. Accordingly, the current $\mathrm{CNC}$ role expanded to include PECC management and service bed management. In order to avoid burnout a plan for recruitment and retention was developed whereby remaining staff were encouraged to take additional management roles of personal interest.

As a result the remaining nurses accepted the challenge of undertaking extra tasks and the development of new skills increased job satisfaction not evident in the early days working 
in PECC. The nurses concerned perceived the extra tasks as a short term venture. However, over time the extra duties developed into more senior responsibilities which the nurses found both educational and challenging. Five RNs identified duties that were above the RN role and submitted proposals for Clinical Nurse Specialist (CNS) positions to St Vincent's Work Force Development Unit. In late 2007 a new PECC management structure and team were implemented.

\section{The clinical team}

The PECC team consists of medical and nursing staff. There is one PECC psychiatrist and three part-time psychiatrists, psychiatric registrars and registered medical officers who cover morning, evening and night shift. The nursing team consists of one CNC, five CNSs, five RNs, and two EENs. Nurses report to the CNC who also coordinates emergency mental health services and ED patient and bed flow at a local level. The CNC provides clinical expertise, consultancy and leadership by maintaining an active role in $\mathrm{ED}$ and is present for complex clinical issues involving staff, patients or carers. A large component of the role includes policy development, participation in relevant Area and State Mental Health committees contributing to best clinical practice development. It involves staff education, supervision, facilitating staff development plans and annual performance appraisals. In addition, nurses report to the PECC psychiatrist about patient treatment, management and planning. The PECC psychiatrist also provides staff education and supervision. Daily three nurses are allocated morning and afternoon and two nurses the night shift. On each shift each nurse has specific areas of responsibilities, two cover PECC duties and the third assumes ED/PECC liaison (referred to liaison from here on) role stationed in ED.

A CNS is rostered on all shifts and depending on staff availability there is often two on per shift. The roles of the PECC RN and CNS are similar in responsibilities for patient care and management. Each nurse is responsible for three patients and coordinates their medical reviews and multidisciplinary team meetings. The majority of the nurses' time is utilised contacting services or families seeking information about the patient. 
The RN and CNS roles differ in that the CNS is regarded as an expert nurse who has the knowledge and skills of a 'sub-speciality' impacting on the mental health and wellbeing of people. For example, each CNS has a self identified area of interest whereby they have elected to become a resource person responsible for educating patients, families, staff and the coordination of specialist services. Areas of expertise include knowledge of personality disorders, early intervention, mood disorders, alcohol and drug management, perceptual disorders and mental health and disability. To maintain current CNS status each nurse must be prepared to provide in-service education on their areas of speciality and act as a resource person hospital wide.

Annually the CNS nurse is given an opportunity to apply for reclassification of the role and is assessed on the date of the initial appointment. Accordingly, the applicant must produce current evidence of having met core key performances as outlined in the CNS job description. For example, a CNS would demonstrate how she/he advanced their clinical knowledge in emergency psychiatry or contributed to either research or education. An important component of the role is an in-depth knowledge of the NSW Mental Health Act, 2007. Another core role of the CNS is to provide clinical leadership, consult liaison resources and demonstrates skills in clinical coordination, patient flow and bed management.

The first PECC nurse role is the 'in-charge' position which is allocated to any of the full time staff. A key function of this role involves management of the unit, allocation of patients to nurse skill mix, ensuring that medical staff, review patients; update risk assessments and complete management and discharge plans. The management of the unit centres on the key aims for patient care which is to, commence or restart treatment, stabilise the patient and link them to key services on discharge from PECC. Another key function is keeping the CNC updated on patient ratio and bed occupancy. The reason is that requests for beds from other mental health services are often accepted or St Vincent's patients who have presented to other areas require repatriation. The medical team will consult the in-charge nurse for bed availability; it is the responsibility of the CNC to negotiate with other health providers for bed occupancy. In situations where a patient 
does not reside in the SESIAHS catchment, bed coordination or repatriation planning is set in motion before admission into PECC. The throughput of patients into PECC varies throughout the week; nevertheless bed occupancy most weeks is full to capacity.

The second PECC nurse is responsible for their allocated patients as well as receiving admissions into the unit. The admission process involves developing care plans using the Mental Health Outcomes Assessment Tool (NSW Health, 2004) supported with other assessment requirements which the patient is encouraged to complete. An important component of the admission process is the identification and reporting of patient behaviours and potential or actual risks to their or others safety. Another key function of the role is escorting patients on transfer to other inpatient units or general hospitals. In these situations organising documentation is involved, faxing of letters, assessment forms and the collating of legal papers is important. An estimated time of departure is negotiated with the ambulance services and accepting health organisation is informed of arrival time. Depending on the level of dangerousness, aggression and agitation security services is requested to accompany the nurse to transport the patient. Both PECC nurses provide assessments, observations, care planning reporting about their patients to on coming staff at shift handover. They are also responsible for the discharge arrangements and referral processing of patients to other appropriate services. Orientation of new staff and mentoring nursing students is undertaken by all PECC nurses likewise the provision of education and resources to patients, families and carers.

The third PECC nurse role is the liaison nurse based in the emergency area responsible for patients with mental health problems referred by the ED triage nurse. The liaison nurse is directly responsible for the coordination of care of patients who require a psychiatric assessment following medical clearance from the ED medical team. Groups requiring assessment include persons affected by drug and alcohol, overdoses and poisonings with the intent to die or who have serious self harm behaviour. Once medical clearance is determined the liaison nurse and psychiatric doctor will review the patient. 
People exhibiting antisocial, aggressive and threatening behaviour without mental health problems are not usually admitted into the PECC and normally are escorted from ED if behaviour escalates. Patients who have behavioural problems and mental health problems are transferred to the inpatient unit.

The liaison nurse may see up to 10 patients a shift. The PECC in-charge nurse can transfer between 5 - 10 patients per week to various inpatient units. The majority of PECC patients will be discharged to the care of their general practitioner (GP), family, and carers or to appropriate services for ongoing care within two days of admission. Occasionally request for longer length of stay in PECC is negotiated with the team and bed manager.

\section{The patient's journey}

The majority of patients either self present or are accompanied by family or friends to ED seeking help from mental health services. Within this group some patients have been referred by other services, clinics or GPs. Some patients may at the time of presentation to ED be unaware that they require mental health support to meet their needs. Another group of patients are brought into ED for assessment by the NSW Police, Ambulance services; Acute Care team or community mental health teams under the NSW Mental Health Act 2007. Under these circumstances, there is direct access to the liaison nurse who will initiate mental health assessment process with the PECC medical team. In these circumstances the PECC team assumes responsibility for the medical, physical and psychiatric assessment. Baseline observations and blood glucose levels are taken, and blood and urine specimens sent to laboratory for analysis. The role of the liaison nurse is to seek data about the patient from old notes or from other services who may have some contact with the person.

In situations where a person who is in police custody requires an assessment, officers will remain with the patient until the assessment completed. The assessment process is the same as above and if the patient is not deemed mentally unwell she/he will return to 
custody of the police. The liaison nurse will ensure that copies of the assessment, management or treatment plan and risk assessment are prepared. In some situations medication is recommended and administered to the patient prior to leaving ED. An exception to this rule is when a person who has a mental health diagnosis or history of mental illness becomes the responsibility of the mental health services. Subsequently, the patient will be admitted into the inpatient unit or a forensic unit. Alternatively if the patient is found suitable for discharge, copies of the assessment, findings and risk assessment is faxed to the person's general practitioner or a follow up request is faxed to acute care teams or community services.

The PECC registrar will consult the ED registrar in regards to the management of patients who are too agitated, violent or aggressive. The process is if appropriate, first offer patients oral sedation medications. However, if rapid tranquillisation is needed both teams will work together in the application intravenous pharmacological intervention. Although the liaison nurse is pivotal in the decision-making process of when, why and who is given rapid tranquillisation. The final is decision made by the ED registrar, PECC registrar and consultant. In these circumstances the management of care is transferred back to the ED staff and reviewed by the PECC team once the patient's behaviour has stabilised. The application of rapid tranquillisation is administered accordingly to the protocols stated in the St Vincent's Hospital ED Rapid Tranquillisation Policy and Guidelines (2007) and the liaison nurse must ensure that documents related to the tranquillisation are recorded and collated.

Patients who require long term treatment, management and care will be transferred to an inpatient bed. Transporting of patients to inpatient units from ED is the responsibility of the liaison nurse. However, seeking bed occupancy in other health areas is managed by the CNC. In circumstances where there are no beds available, patient swap is considered by the bed managers involved. Alternatively, an inpatient who is stable and considered suitable for PECC is transferred from Caritas (St Vincent's inpatient unit) creating a bed for the new arrival. Patients who may benefit from a brief stay following an acute crisis situation are usually considered suitable for admission into PECC. Importantly, the liaison role is designed to provide rapid assessment and intervention for psychiatric emergency 
care at the point of contact with hospital emergency staff. The aim is to ensure that all referrals are seen in a timely manner and that patients are offered mental health treatment or linked in to appropriate services.

An important component of the liaison role is ongoing education and provision of mental health resources to ED staff, patients, families and carers. All CNS and registered nurses (full time PECC nurses) undertake the liaison role and are in direct contact with the CNC for the management outcomes of ED presentations. The relationship between the CNC and liaison nurse is based on the principles of safe practice, leadership and support. An example is the $\mathrm{CNC}$ is available at all times when required and is personally involved the care of people with complex needs.

During the hours of midnight to 8am there is no PECC medical officer on duty, however, an on-call registrar is available for all consultations. Patients who self present to ED during these hours are either assessed by the duty CNS or senior RN who in consultation with the ED registrar will develop a management plan. The availability of these nurses to complete assessments in ED depends on the availability of a mental health nurse seconded from the inpatient to cover PECC until assessments completed. Alternatively and depending on the acuity of ED, a nurse may also be seconded to PECC. This important process is upheld because of safety reasons and two nurses remain in the unit at all times.

The management of acutely unwell patients and those who are drug induced or intoxicated are cared for by the ED staff until medically cleared or referred to the liaison nurse in the morning. In these circumstances the ED registrar will confer with the on-call PECC registrar. The decision to admit any patient who may benefit from an overnight stay in PECC can be made at the discretion of CNS in consultation with the on-call PECC registrar. This process ensures that registrar will inform the consultant of the day whereby all admitted patients have access to specialist care. Before any patient is admitted into PECC they first must be accepted by the on-call consultant. Patients who have remained overnight in ED are reassessed, and, those who may have presented early hours in the 
morning and not seen are assessed within the hour. The night shift CNS or RN will hand over to the morning shift liaison nurse the list of patients and activities involved in their care. The aim is to check the status and documentation of each patient in preparation and prioritising them according to urgency of care required.

\section{Documentation in patient notes}

Documentation is an important part of all nursing roles. There are legal requirements in the reporting of patient's day-to-day care as well as maintaining patient confidentiality. On each shift PECC nurses are responsible for reporting patient's mental status, changes in behaviour, non adherence of medication or treatment, and risk levels including dangerousness toward others, self harming behaviours, suicide and homicidal intent. Patients' notes are regularly audited by a service especially selected by the national mental health service to monitor the documentation of notes and patient care. Scheduled patients under the NSW Mental Health Act 2007 have specific guidelines for documentation as to when, why and where a patient is diagnosed with a mental illness or mental disorder. Incorrect documentation can result in an un-well patient being unscheduled and discharged back out in the community.

Incident reporting is another important aspect of documentation. The quality improvement unit oversees all incident reports which are written on electronic template called the 'Riskman'. Documentation aims to protect nurses from missing vital information regarding delivery of patient care and provides a framework to guide treatment toward the patient's recovery.

\section{Security Service}

The safety of public, patients and staff is pivotal to the delivery of health care and the hospital security service plays a vital role in maintaining the safety of all concerned, be it within the hospital or its surrounding parameters. Request for security assistance is through activation of personal duress and hard wire duress alarms or dialling the hospital Emergency 555 number. The security team will assist in high-low violence risk situations, 
apprehend absconders who are scheduled under the NSW Mental Health Act 2007 and assist with persons with special security needs in the ED, for example, victims of crime.

The security team assists PECC staff when patients are bought to ED by the police or Acute Care team. Before assessment commences the patient is searched using the security metal detector for articles that can be potential weapons or used for self-harming behaviours. These include belts, laces, lighters, mobile phones with cameras and chargers, sharp utensils and solutions of all kinds. Patient personal property is documented, labelled and put into a locked cupboard or for safe keeping. Jewellery, money, passports and bankcards are locked in the ED safe. Retrieving articles from the safe is done under the supervision of the security team.

The security team assist PECC staff with agitated or violent patients. The team are effective in the management of patients who have behavioural problems and/or are abusive, intoxicated or threatening staff. Nevertheless it is the clinical staff responsibility to direct the appropriate strategy in managing these patients. The security office is adjacent to the PECC unit and ED which allows for an immediate response time when the alarm is activated. Security staff will accompany PECC nurses to transport aggressive patients via ambulance to other health providers.

\section{Triage process to ED}

Patients who present to ED are triaged according to the Australian Triage Scale (St Vincents, 2008a). The aim of the triage process is to identify and categorise risk according to the patient's description of health problem and level of urgency of the responses required. The assigned triage category is based on clinical presentation and degree of risk to self and others. Once a person's rating is established, patients will have access to medical and mental health specialist care. Patients however, are not directly triaged to the PECC. 
Triaged patients who fit under the category of voluntary status are referred to the PECC team following a medical assessment by the general ED medical staff. Referrals to mental health services are accepted from families, public, psychiatrists, general GPs, police, community teams, drug and alcohol services, self presenters, including homeless persons and persons seeking addiction services. Furthermore, referrals are accepted from drug and alcohol services, consult liaison team and pharmacology services. In these circumstances there is dual management of care whereby individual services or team retain responsibility and liaises with PECC staff who maintains a caretaker role.

Table 1: Emergency Department Triage Categories used in Mental Health

\begin{tabular}{|c|l|l|}
\hline CATEGORY & \multicolumn{1}{|c|}{ ACUITY } & \multicolumn{1}{|c|}{ PRESENTATION } \\
\hline 1 & Immediately & $\begin{array}{l}\text { Immediate Risk to Self or Others } \\
\text { Acute Agitation/Violence }\end{array}$ \\
\hline 2 & Within 10 minutes & $\begin{array}{l}\text { Escalating Risk to Self or Others } \\
\text { Agitation / Threats of Violence }\end{array}$ \\
\hline 3 & Within 30 minutes & $\begin{array}{l}\text { Risk to Self or Others } \\
\text { Confusion/Withdrawal/Intrusive }\end{array}$ \\
\hline 4 & Within 1 hour & $\begin{array}{l}\text { Low Risk to Self or Others } \\
\text { No Agitation/cooperation/coherent }\end{array}$ \\
\hline 5 & Within 2 hours & $\begin{array}{l}\text { No Risk to Self or Others co-operative } \\
\text { communicative /complaint with } \\
\text { instruction }\end{array}$ \\
\hline
\end{tabular}

*Source: St Vincents. (2008a). Psychiatric Emergency Care Centre (PECC) Operational Manual (p. 11).

Excluded from routine admission to PECC are children under age 17 years. However, in exceptional circumstances young patients can be admitted. Decisions for admission usually involved several agencies whereby the appropriate services are involved the care of these patients and nurse specials are assigned to monitor them to time of discharge. In all instances these patients were waiting for available placement and transfer to adolescent mental health services. Other patients who are excluded from PECC admission are those with severe medical problems and those who are behaviourally disturbed. Those 
included are patients who need longer than 48 hours admission and those who do not have a mental health problem (St Vincents, 2008a).

Patients who are intoxicated, drug overdoses, lethal suicide attempt (hanging, slashing or gas inhalation) and others are scheduled under the NSW Mental Health Act 2007 for safety reasons whereby they may be at risk to self or others. While these patients may require medical intervention and are the responsibility of the ED staff, the liaison nurse and PECC doctors are involved in the management of these patients. As soon as the patient is medically cleared by the ED team these patients are referred to the PECC team for mental health and risk assessment. Patients first must be accepted for admission into PECC by a Consultant Psychiatrist or ED Staff Specialist. The following assessments will have been completed before the patient leaves ED. They include;

- Initial medical and mental health assessment

- General observations completed of temperature, pulse oximetry, heart rate, blood pressure, blood sugar levels, urine screen, bloods taken and Glascow Coma Scale

- Completion of mental health assessment with provisional diagnosis, treatment plan and care pathway

- Completion of risk assessment of suicide, self harm; potential for violence and absconding without leave.

Patients suitable for PECC admission are those who are stable but have a mental health and medical diagnosis which needs monitoring and management. Included are patients with mental health diagnosis in need of further investigations to exclude or manage organic or co-morbidity problems and those requiring a brief admission for management of existing mental health problems (St Vincents, 2008b).

\section{Admission process to PECC}

The PECC offers a secure and therapeutic environment in which patients receive rapid specialised treatment and admission up to 48 hours. PECC also is utilised by patients in 
the care of community and inpatient services for stabilisation and continuity of care. However, there are no direct admissions into PECC and patients are first processed through ED. The criteria for PECC admission is demonstrated in the algorithm (Figure 1). Firstly a patient's provisional diagnosis indicates psychiatric illness or disorder. Secondly, patient requires brief admission less than 48 hours and finally the patient is accepted by the PECC psychiatrist or on-call. While the PECC registrar is responsible for negotiating with the psychiatrist for the patient to be admitted to either PECC or Caritas, it is the role of the bed manager to accept or decline an admission.

\section{ALGORITHM FOR PECC ADMISSION}

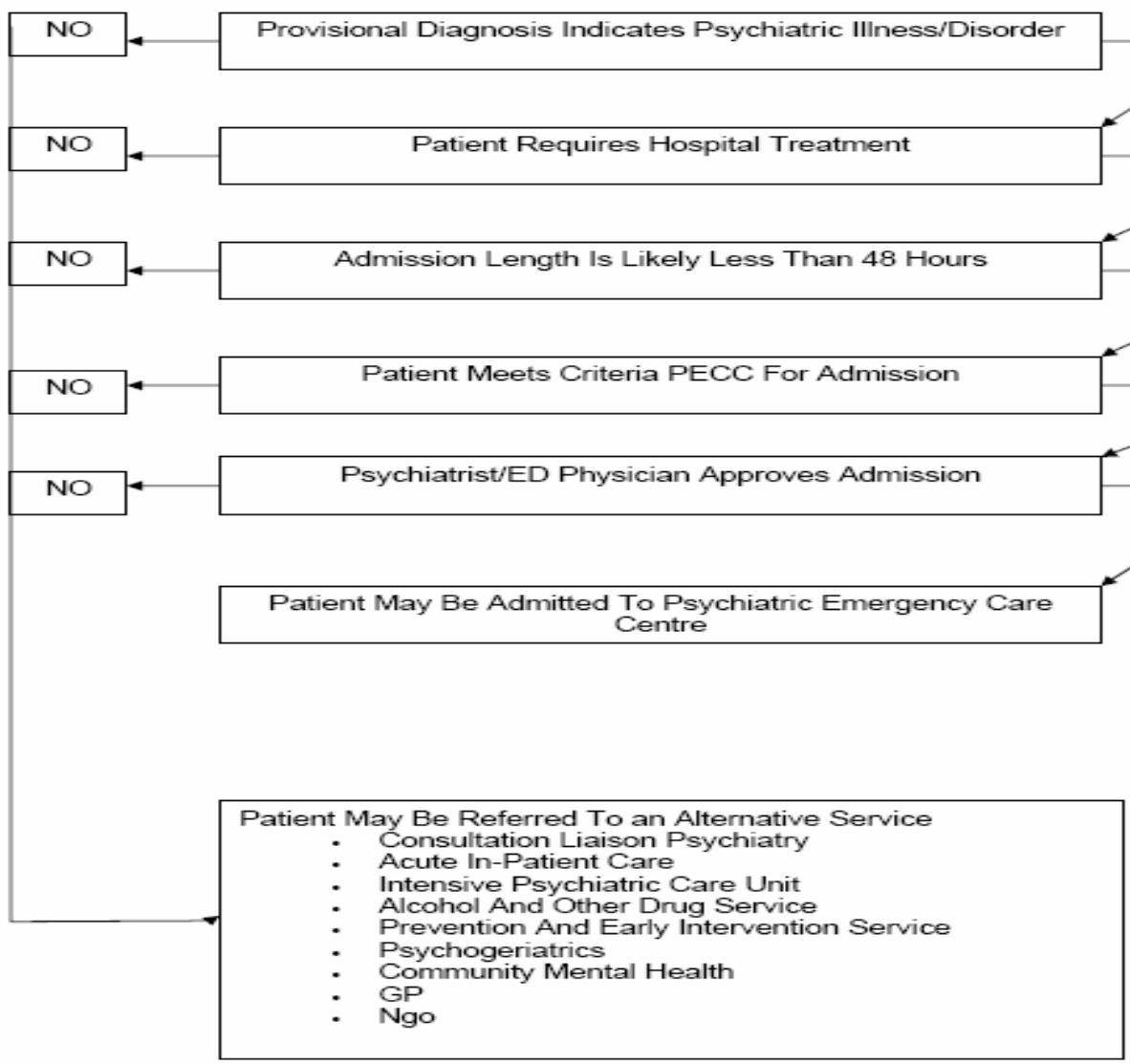

\section{Figure 1: Algorithms for PECC Admission}

*Source: St Vincents. (2008a). Psychiatric Emergency Care Centre (PECC) Operational Manual (p. 13). 
PECC beds are limited to six and no admissions over this number are permitted. If a patient is identified as requiring a bed, and the PECC is full to capacity, then alternatives for admissions include seeking transfer to another PECC or initiating bed flow measures within or managing the patient in ED are adopted. However, the last option is not widely accepted by ED or Area Health Bed Management Office because of possible long length of stay in ED. Accordingly patients must be discharged from the ED no longer than 8 hours.

\section{Mental health presentations to emergency department and PECC}

The figures show significant increases in the annual rates of mental health presentations to ED (Table 2) while PECC admissions have remained relatively stable since the formation of the service. The total number of patients admitted to PECC from when the service opened is 2153. This increase in the number of presentation to ED is in line with mainstreaming mental health services and the creation of a single point of entry to mental health services through the ED.

Table 2: Mental health ED presentations and PECC admissions 2005 - 2008

\begin{tabular}{|c|c|c|}
\hline Year & ED Presentations & PECC Admissions \\
\hline 2005 & 2,833 & 48 \\
\hline 2006 & 3,847 & 693 \\
\hline 2007 & 4,911 & 698 \\
\hline 2008 & 4,987 & 714 \\
\hline TOTAL & 13115 & 2153 \\
\hline
\end{tabular}

The figures and tables identify the statistical aspects of the ED presentations and admission to PECC which have been gathered from Hospital Patient Administration System (HOSPAS) and Emergency Data Information System (EDIS) data collection programmes within St Vincent's Hospital. Also, data included was manually analysed and contrasted from the patient register within PECC. 
The figures for ED presentations have increased from 2005 to 2008; full year data for 2006 compared with 2008 indicates a 43.19\% increase whereas PECC admissions have only increased $2.02 \%$ over the same time period. On average the number of presentations to ED for mental health assessment and intervention (referral on, admission or community follow) are 9.3 per day. Over the period that PECC has been fully functional there has been a steady increase in the number of presentation and assessments conducted within the ED. The data analysed has identified that there has been a $43.19 \%$ increase in presentation to the ED.

As Figure 2 shows more males than females were admitted to PECC between November 2005 and December 2008.

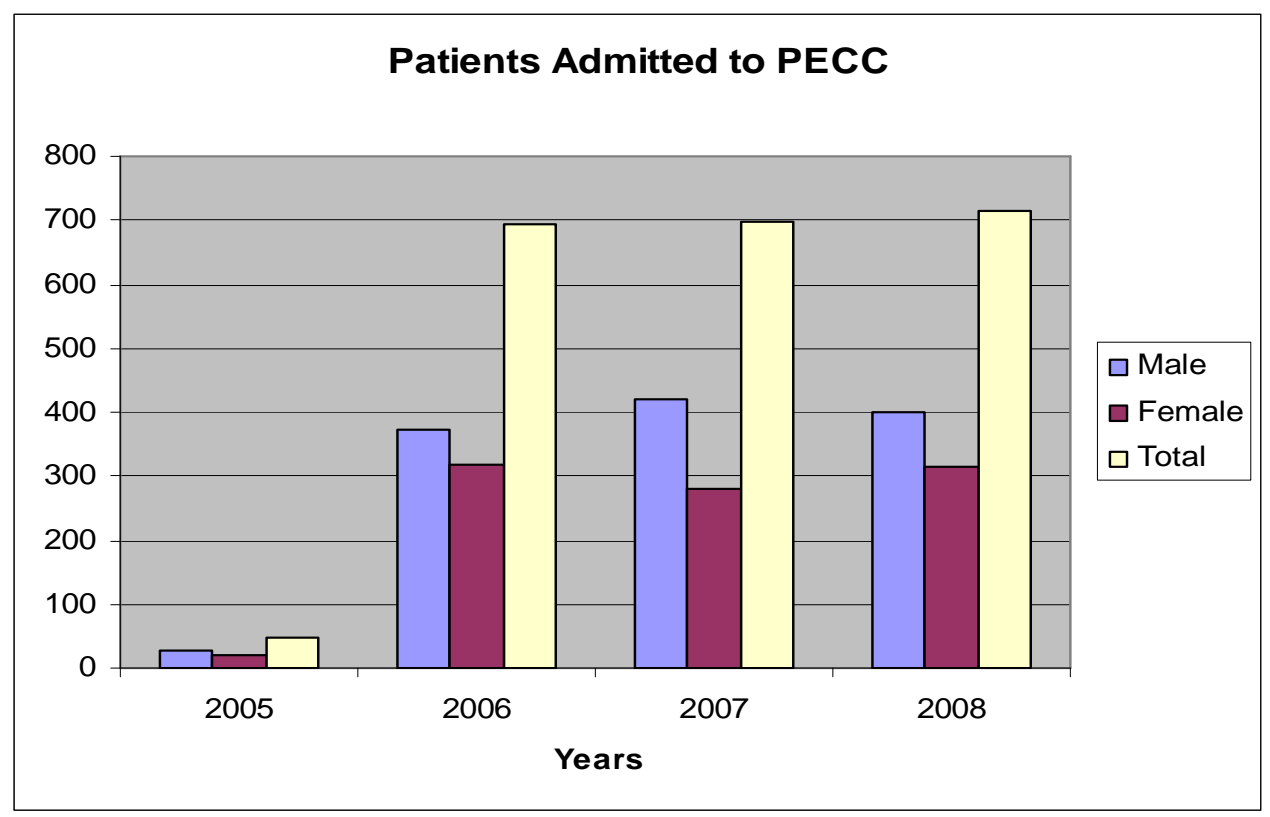

Figure 2: Total mental health patients admitted to PECC 2005-2008 
Figures 3 and 4 present the findings over the years by age and gender. These figures show there are no clear patterns for all age groups, with the most common age groups for both genders being 25-34 and 35-44 years.

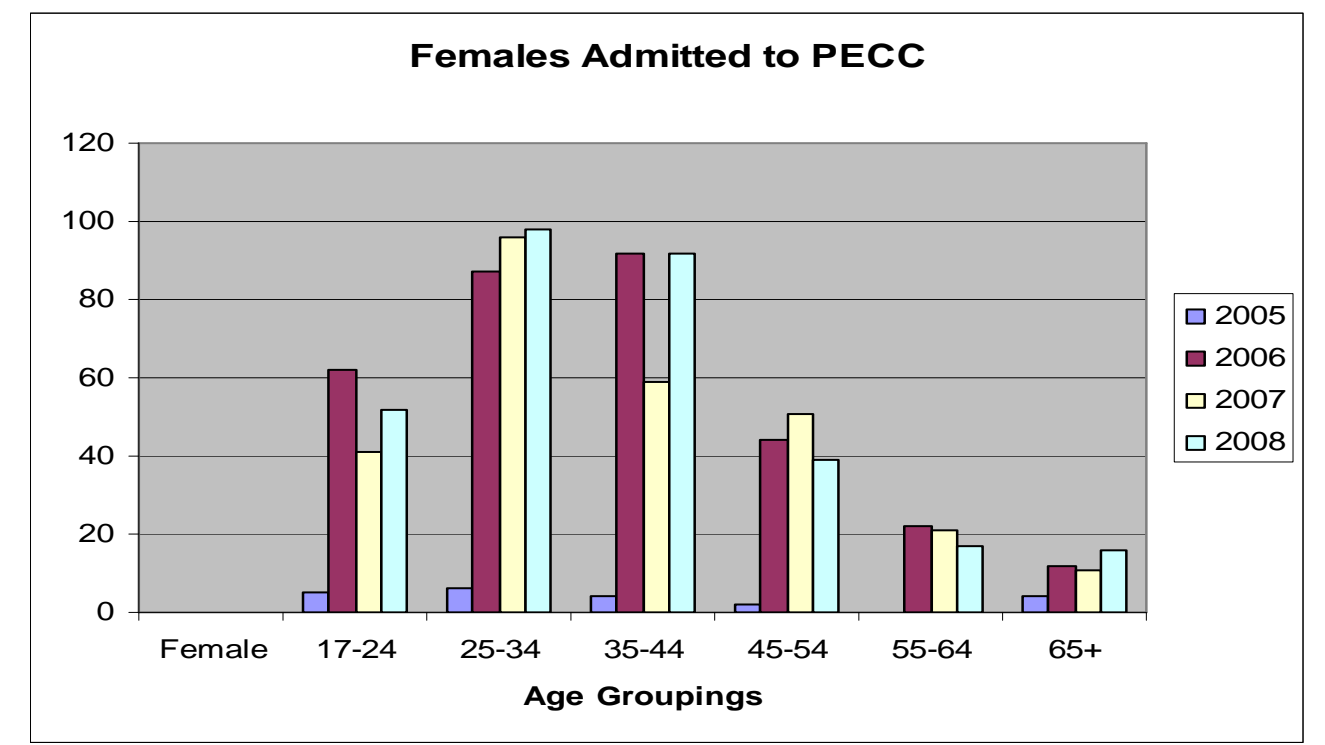

Figure 3: Females by age and year of patients admitted to PECC 2005-2008

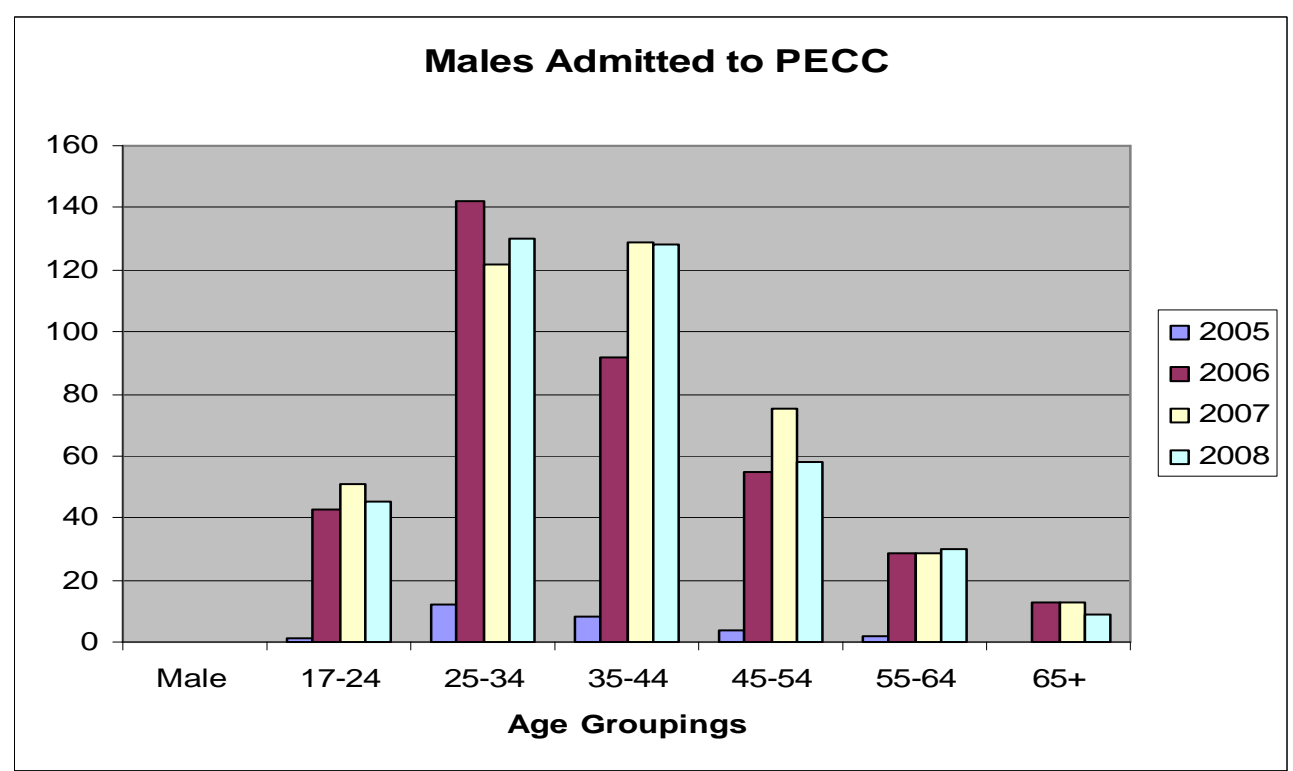

Figure 4: Males by age and year of patients admitted to PECC 2005-2008 


\section{Bed Management}

Bed management role is the responsibility of the CNC however, the liaison nurse assumes the role after $6 \mathrm{pm}$ and when the $\mathrm{CNC}$ is on days off or on leave. Bed management role is undertaken by PECC nurses who work in the liaison role. It involves effective communication, coordinating and negotiating skills in the management of patient flow.

Patient flow within ED in terms of length of stay is monitored by SESIAH bed coordinator therefore the CNC or bed manager will regularly update SESIAH on the bed occupancy of PECC and mental health patients in ED. Bed reports are prepared at the beginning of each shift confirming bed occupancy in triage, ED, PECC and the inpatient unit and forwarded to SESIAH. The aim is to avoid bed blockage in ED and maintain patient flow into the appropriate services. In circumstances of bed blockages occurring in the PECC or inpatient unit, beds are then sought after, first within the local area health services and secondly from other areas.

A factor that impacts on bed shortage in St Vincents is its locality. Many patients who present to ED are holidaymakers and people who live in the outer suburbs of Sydney. Another reason is the easy access to alcohol, party pills and designer drugs preferred by young folk seeking the popular dance party scene. The locality is certainly the case for majority of police presentations to ED needing psychiatric assessment. St Vincent's hospital is surrounded by many hotels, restaurants and cafes. Attempts to repatriate patients back to their local hospital are usually unsuccessful because of reported bed shortages. Consequently many patients admitted into PECC or inpatient unit are from out of area and often block beds allocated for St Vincent's patients. Nevertheless, since its inception the PECC unit has had a positive impact on improving patient flow and reducing delays in ED. A positive outcome is the development of excellent working relationships between the ED and PECC teams and sharing of resources and knowledge. It is maintained through communication and consultation with each other. The effect has shown improvement on service delivery and patient care and to date there has been minimal numbers of absconding patients from the $\mathrm{ED}$ and no reported post discharge suicides. 


\section{Role Effectiveness}

While the new care model has given the nurses in the PECC unit more autonomy and recognised the increased responsibilities for care of patients there is no evidence available on whether the new RN roles are effective. Currently effectiveness is measured by the monthly Bed Capacity Report, which reflects the monthly totals of patient numbers seen and PECC admissions. The culture is that we assume we are doing a great job because of our high patient turnover and low recidivists and no post discharge suicide. There is considerable literature around the establishment and effectiveness of PECC units that identifies a clear need for such units, however,, role effectiveness of nurses in this area that has not been researched.

\section{Summary}

This chapter has described how St Vincent's PECC service evolved and provided an overview of the roles of clinicians especially the nurses who work in it. It highlighted the relationship between ED and other services for PECC nurses to work effectively in the ED. The following chapter presents an overview of the methodology chosen for this research. 


\section{Chapter 4: Evaluation Methodology}

\section{Introduction}

This chapter is written in two parts. The first part describes the methodology evaluation research drawing on literature to background and explain the approach involved. Evaluation research involves systematically acquiring and accessing information for formative, process and impact or outcome purposes (Trochim, 2006). The information therefore assists in the "decision making processes and [is] used to develop quality programs and services" (Unrau, Krysik, \& Grinnell, 2005, p. 474). The second part describes the research design for the project.

My arrival at St Vincent's Hospital resulted in my entering a new cultural environment where the model of practice was one not seen in the New Zealand. As a Māori the need to understand the kaupapa (scheme, subject, theme, and programme) of my new environment was essential. This, along with the knowledge that the model of care was successful as evidenced by the case load for the service increasing by $1.1 \%$ annually led me to seek a methodology that could systematically describe the service. While there are various types of research approaches that could have been utilised, evaluation research was the methodology chosen to describe and review the Psychiatric Emergency Care Centre (PECC) service. The impact of this new service on consumers and PECC and emergency department (ED) nurses was the focus of the evaluation. The evaluation's purpose was to inform stakeholders of potential service improvements and inform ongoing development.

\section{Exploration of evaluation methodologies}

Evaluation methodologies are traditionally supported by positivistic perspectives and values of scientific inquiry in that they often utilise numerical and statistical methods of analysis that are objective, measurable and replicable (Walsh et al. 2007). There are wide diverse viewpoints surrounding essential requirements for effective evaluation in contemporary settings. These require inclusiveness of unique stakeholder views which 
have resulted in more expansive inquiry that utilises a variety of methods (Hall, 2004; Walsh et al.). Evaluation is politically and fiscally important in today's complex health environment where funding is transient and accountability to stakeholders, especially to patients, is an increasing focus. Evaluating the consequences of actions is fundamental to health services and nursing practice.

While there are various definitions of evaluation I concur with Koch's (2003) definition of "evaluation is applied research for the purpose of informing action, enhancing decisions and making and applying knowledge to solve problems identified in practice" (p. 233). Evaluation research in clinical practice is utilised for the purpose of investigating how well a programme, practice or policy is working (Polit \& Beck, 2006) and "includes any effort to increase human effectiveness through systematic data based enquiry" (Patton, 1990, p. 11). As such the aim is to determine the impact or effect of an event, intervention or organisational change on health service, its staff or patients.

The need for evaluation research in health has increased over the past two decades prompted by the growth of evidenced-based practice and the high costs of healthcare (Walsh et al. 2007). Indeed, the impact of government agencies, professional organisations, and individual calls for evidenced-based practices in the clinical settings has seen an emergence of evaluation research utilised in the development of health policies, quality assurance programmes, health education and promotion, human resource management and services development (Koch, 2003; Nelson, Steele, \& Mize, 2006). Peterson (1997) maintains that as "economic contingencies and policy planning imperatives have increased so too has the demand to account for the success of programmes and to plan for the most effective use of resources" (p. 98). As demand for evaluation of programmes or services by public agencies gathers momentum to demonstrate effectiveness which in part involves performance measurement, policy development and practice to be more accountable and evidenced-based (Wimbush \& Watson, 2000), problems have occurred because of the complex relationship between the health system and health care delivery which involves human interactions and practices based as much on custom and practice as on evidence (Walsh et al.). 
To a large degree evaluation research is firmly established in social and public policy texts (Ellis \& Hogard, 2006) while information is limited in nursing literature (PolitO'Hara \& Hungler, 1995). Historically, political changes in the United States of America and the need to analyse social programmes that did not appear to be working saw the rise in evaluative research. Accordingly, applied social policy methodology increased in status because of the need to logically analyse costs and benefits associated with programmes (Meyers, 1981; Robson, 1993). Evaluation research addresses these issues, which is appealing, however, quality issues associated with this research often lead to negative criticism. One way to address criticism is to demonstrate how research findings will be promoted (Patton, 1997). Furthermore, limitations can be reduced by ensuring a comprehensive process that addresses financial, performances and management issues and by determining the evaluation meet specific purposes.

\section{Process and impact evaluations}

Process evaluation describes and analyses the way a new programme or procedure operates and assesses how the impact activities of the intervention can be used to interpret outcomes and inform future planning (Polit \& Beck, 2006; Viadro, Earp, \& Altpeter, 1997). Process impact evaluation (particularly of new services) needs to be all inclusive, and can be achieved by considering two key evaluation approaches; process and impact or outcomes. Process evaluation involves a comprehensive review of the program/services' activities, programme quality and who it reaches. It can also establish the degree to which a programme is operating as intended. Impact or outcomes evaluation measures the effect of the service or programme in relation to service objectives and what impact a programme has on health (Hawe, Degeling, \& Hall, 1990). According to Owen (2006) although the emphasis of an impact evaluation is on outcomes, such evaluations can also result in a review of the characteristics of a programme. In the case of the St Vincent PECC service the intent was to determine what works well and what doesn't in the service that could then be used for further development. 


\section{Study design}

The evaluation was designed to complement existing evaluations by examining the activities of the service since its inception and its impact on the ED and other key groups. Existing evaluations of the service include consumer satisfaction surveys. Particular foci of the evaluation were to understand the roles of the PECC nurse and how they deliver their service and to establish what is presently understood about how well the PECC services met the needs of those with mental health problems who accessed the service. The evaluation's purpose was to inform key groups of what works well and what can be improved and to inform the PECC team of potential quality improvements for the service.

The study design adopted a mixed method approach using three main types of data. The data types were:

- National and local documents;

- Existing national and local statistical data; and

- In-depth interviews with a group of stakeholders.

In addition, given the researcher's role in the PECC service, personal knowledge and experience of working within the service were used to elaborate and explain the data.

National and local documents collected included the New South Wales Standards for Mental Health Services (NSW Department of Health, 1997), and the National Mental Health Plan (Australian Health Ministers, 1992b). Further information was obtained though a library search that included specific PECC documents from local and regional sources. These were analysed for background information and how PECC evolved in New South Wales (NSW) and why this occurred. Topics of interest were evaluations of the working group involved in mental health, analysis and service specification and provision; education and training in the emergency department and models of care (NSW Department of Health, 1998). The findings from these documents were used to describe the development and background of the service in Chapter 3. 
The national and local figures reported in Chapter 3 were generated by gathering data relating to patients who were triaged in ED with mental health problems. Data were extracted from the hospital's HOSPAS and EDIS information systems and then transferred to an Excel spreadsheet so that admissions were identified by year of initial assessment, gender and age. Included were PECC admissions of actual bed occupancy from November 2005 to August 2008. The purpose was to establish the number of patients who were triaged in ED and seen by the PECC nurse at the emergency department. The total numbers were categorised into gender and age groups as a basis to compare with ED population data. These yearly trends were converted to graphs for reporting purposes. Pre-existing organisational data were collected, utilising information already in the public domain.

A decision was made to interview PECC nurses, ED nurses and consumer representative. Three interview schedules (Appendix 5, 6\& 7) were developed based on questions arising from the literature review and the researcher's knowledge of the service. Interviews were conducted by the researcher. The questions for each group were similar in focus. Structured questions were used to seek information from participants regarding positive and negative aspects of the PECC and liaison nurses' roles, their views on the impact of the service and their suggestions on what could improve the service. All interviewees were also to be invited to comment on the skills and knowledge required and utilised in each of the nurses' roles and what could be improved from a nurse's or consumer's perspective. In addition, PECC nurses were asked to describe their professional qualifications and clinical experience and whether supervision was part of their professional practice.

\section{Recruitment of interviewees}

The PECC nurses who had worked at the service for six or more months were invited by email to participate in the study. In addition, an ED registered nurse and a consumer representative were approach by the researcher because of their extensive experience working in a variety of situations with PECC staff and mental health consumers. These people were chosen for their experience in working with the PECC team because it would 
have been difficult to recruit volunteers in this area because of the small numbers involved and the time factor. My knowledge of this as an internal researcher assisted in this process.

Participation was voluntary and participants were aware that all information gathered would be kept confidential. Prior to being interviewed it was expected that participants would be given an information sheet (Appendix 2) about the study terms, and consent form (Appendix 3) agreeing to participate and revocation of consent form should the participant decide to withdraw from the study (Appendix 4).

Researcher trust and honesty were important in this research. To ensure privacy and protection of the participant's identity and interview responses, participants were informed that all information and the recordings would be locked in a personal designated cabinet and the tapes destroyed one year after the completion of the research. The tapes were only heard by the researcher and supervisor but were available to the participant if they wished to hear their comments.

The initial plan to interview all participants was reviewed with the supervisor because of low response from PECC nurses. While all PECC nurses were supportive of the study and agreed to be interviewed, a number of participants requested to provide written responses instead. Their reasons were:

Too time consuming; Need time to think about answers; I don't like being interviewed; Too busy to meet for interview; I am going on leave; Unsure if I can make the interview appointment.

Time and distance in travel to meet for appointed interviews were major factors for the request of written responses. A significant number of nurses travel between 45-90 minutes to and from work on public transport and at the end of their shift 'rush off' campus not to miss transport home. Therefore, a generalised reluctance to participate in 
interview after work, or on a day off, was understood by the researcher. Participants were informed that written submissions would be an acceptable method of data collection for this study. Subsequently, written responses were accepted from some registered nurses.

\section{Analysis of interview data}

Each participant interview response or written response was analysed separately for content and themes. As the interviews were constructed to allow for different perspectives during the analysis I needed to be open to difference. The content and themes for each question from all interviews were then combined to establish similarities and differences. The interview transcripts and questionnaires related to each question were then read to establish that all perspectives raised by interviewees had been captured in the themes that emerged. After themes for each question were confirmed, triangulation of themes across all questions took place. The interview transcripts and questionnaires were read for a final time to review that the analysis reflected the interview and questionnaire content. The findings from these interviews are presented in the following chapter.

\section{Rigour / Quality}

Rigour in this evaluation related to three key areas: evaluator credibility, trustworthiness of data and consistency. Credibility involves the "degree to which the evaluator is credible and believable" (Owen, 2006, p. 115). Areas that impact on credibility relate to the researcher's objectivity and accountability. Internal evaluators gain trust and respect over time in their work environment (Owen). As a clinical nurse specialist, with advanced qualifications in mental health and education, along with proven clinical expertise, fairness and honesty in working with colleagues and consumers, I was seen as credible to those who volunteered. As an educator I was able to debate the benefits on doing this to not only the organisation but to all the key stakeholders and convince them of the potential of this research to act as a platform for further projects and to improve services. Seeking permission from St Vincent's Hospital Human Research Ethic Committee required that I had a credible history and they were able to trust my ability to carry out this research. Also, the ethics of the study were well articulated and issues addressed. 
Trustworthiness of data can be measured by using various methods to check reliability of data (Polit \& Beck, 2006). In this research different sources of data were triangulated by comparing information interviews with the other data. Participants were able to cross check the outcomes to ensure this matched their interview response resulting in triangulation through rechecking with the participant for verification. This is especially important where qualitative discussions occur. Triangulation helps to counterbalance biases from any one data source (Polit \& Beck). Other methods utilised in the research to ensure data trustworthiness was the strategy of using the participant to listen to their recording and check on themes to ensure accuracy of interpretation and limit bias through the analytical process. Also, cross member checking was utilised in this research and a service manager read a full draft of the thesis two months prior to submission. According to Polit and Beck the use of cross member checking increases the quality and validity of the research through checking and rechecking of information that has been given.

Ensuring consistency in this study was done in two ways. Firstly in all interviews participants were asked questions in a similar format as outlined in the interview schedule. This ensured that the interviews could produce the information for the investigation. Secondly a systematic approach to the analysis was undertaken which involved examining each interview transcript and questionnaire separately using a standardised approach.

\section{Ethical considerations}

Ethical considerations for this study had to comply both with Australian requirements given the setting of the research and with New Zealand requirements where I was enrolled in my studies. An application for approval to conduct the study was submitted to the Victoria University of Wellington Human Ethics Committee in September 2008. The application was then forwarded to the St Vincent's Hospital Human Research Ethics Committee (HREC). 
Approval was not initially gained from St Vincent's HREC who required that the researcher gain permission to interview ED staff from additional senior clinical directors. Approval from the Director of St Vincent's Mental Health Service (Appendix 8) was given in the planning stage of this thesis. A second application with the required amendments was resubmitted, however, St Vincent's HREC had further requirements including that the researcher utilise St Vincent's Hospital Participant/ Consent Information Sheet and Consent Form. Approval was finally obtained in December 2008 from St Vincent's HREC (Appendix 9).

Patients rights were upheld as no case notes were reviewed and none were identified within the interviews. Confidentiality of information disclosed was maintained as determined in the consent forms and confidentiality contracts between participants, researcher and organisation. The participants were informed that there were no foreseen risks in participating in the study as it specifically aimed at obtaining information about how the service work and no personal health information would be collected.

All efforts were employed to protect the identity of the participants within the research, however given that the PECC service is small; that PECC and ED staff are interested in the evaluation; and that representatives from the Consumer Group are generally known, local people may be able to identify or know who is involved in the study. Participants were warned of these possibilities and that quotations from the interviews would be used in the final thesis but not identified by individuals rather by the interview group, for example PECC nurse; ED staff member and Consumer representative.

\section{Summary}

Evaluation methodology is increasingly important as a means of identifying accountability in today's complex health environment. Evaluating the consequences of actions is fundamental to best practise, informing action, enhancing decisions and ensuring problem solving issues identified in practice especially when consumer needs are identified. Evaluation research was identified as the most appropriate method to 
evaluate the St Vincent's hospital PECC service. Discussion and ethical approval identified that the utilisation of an internal evaluator who was trusted to meet ethical considerations allowed for easier differentiation of interview questions that were appropriate and relevant for the service. This systematic process impact evaluation methodology allowed the researcher to investigate the model of care which had not been evaluated previously in this setting to determine the impact on stakeholder. The following chapter presents the findings from this process. 


\section{Chapter 5: Findings}

\section{Introduction}

This chapter presents the findings of individual face-to-face interviews with four nurses and a consumer representative and the written responses from four nurses involved in the Psychiatric Emergency Care Centre (PECC) service. The aim was to examine participants' perspectives about the PECC service, role of the PECC and liaison nurse. The focus of the interviews was to establish how the PECC service operates, identify what works well and what can be improved and to inform ongoing development. This was accomplished through obtaining different perspectives from participants based on their experience and understanding of PECC service provision.

\section{The interviews}

The interviews on average went for 90 minutes with a range of 1-2 hours. The first interview took two hours due to the researcher's inexperience operating a voice recorder, compounded by the position of the venue where the interview was held. The venue was close to a bus station and the background noise interfered with the quality of the recording. A change of venue and new voice recorder assisted in the improvement of quality of recordings. As a result of this experience I was better prepared for the next interviews and these went smoothly. Notes were taken during interviews highlighting points participants shared, pertaining to a particular question of interest. Verbal prompts were used throughout the interviews to rephrase questions participants had difficulty responding to.

Four written responses were provided within 3 weeks of the request, and ranged from 3 to 10 pages. Although it is usual to refer to interviewees as participants and written responders as respondents, this distinction is not made here rather all nurses are referred to as participants as is the consumer representative. 


\section{PECC experience of participants}

The eight nurses were experienced registered nurses who had been working in the PECC and Emergency Department (ED) between 6 months to 7 years. Of these four had been involved with PECC from the time of its inception and four between 2006 and 2008. Their clinical backgrounds varied from mental health nursing only to, include general, emergency and trauma nursing and management. The consumer representative had been involved with other mental health services at a local and national level for several years.

The nurses had a range of qualifications in addition to their registration. One nurse held three hospital certificates in general, psychiatric, child and adolescent nursing and another two hospital psychiatric certificates; five nurses held a diploma and one held a bachelor degree. Two nurses were enrolled in post-graduate studies; one had completed two Masters Degrees, one by course work and one by research, and other nurse had a Post Graduate Diploma and was mid way through completing their Masters. Other nurses were not engaged in any formal post-graduate studies however, two were in the process of seeking suitable courses and learning institutions. Some nurses reported that they had attended hospital and external courses but did not specify them. One identified a course attended, Psychosocial Interventions: working with people who experience serious mental health problems.

\section{Mental health experience of participants prior to PECC role}

The nurses had worked in various mental health areas prior to working at the PECC service. These included working in community teams, acute to sub acute child, adolescent and adult inpatient units, consultation and liaison, forensic, brain injury and developmental disability, psycho geriatrics and in a HIV mental health team. Two nurses had worked in senior management roles; one as assistant nurse unit manager and other as Director of Operations: child and adolescent mental health services, Clinical Nurse Consultant (CNC), consultation liaison, nurse unit manager adult services, crisis and trauma. 
Six nurses said they joined the PECC service because the role sounded and looked exciting and they were attracted to the concept of a new service project. Two others had previously worked in PECC as agency nurses covering staff shortages due to sick and holiday leave of permanent staff. They described their experience as enjoyable and supportive. Nurse 1 said "I enjoyed working in PECC and applied for a job when ....left. In contrast Nurse 2 said "The staff easy to work with and helpful. Submitted my portfolio and was successful". Another nurse (Nurse 3) had used the services of a nursing agency to find a suitable position in a mental health service. For them a factor for accepting the role in PECC was that it "provided opportunity for personal and professional development in mental health" (Nurse 3).

Nurse 4 commented on the recruitment of staff to the PECC services. This nurse considered that PECC jobs were poorly advertised and people only found out about them by word of mouth. Frustration was expressed in terms of; "I haven't seen any advertisements anywhere? As I long as I've been here we've always used agency nurses; waste of resources and time we do all the work anyway." No information was available on the staff turnover or use of agency nurses to substantiate this picture.

\section{Strengths of the PECC Service}

The nurses reported the varying skills and experience of the team were the strengths of the service. The most common view was the leadership skills of the PECC CNC. Strengths were described using one or more of the following terms: Nurse 7 sums up what many nurses said namely;

Cultural diversity of staff; combination of different skill mix; autonomous practice that is respected by peers and medical staff; nurse-led unit; experienced nursing staff; cohesive team, high quality nursing practice; calibre of nursing knowledge equals that of a clinical nurse consultant; team led by a encouraging and supportive leader. 
Two nurses also identified the role and function of the liaison nurse which they thought was important to facilitate patient flow and to link secondary services to primary services. For Nurse 1 this linkage was dependent on the "liaison nurses knowledge in medical and psychological assessment, treatment and management of mental health patients ensures the patient receives appropriate care and services" but for Nurse 2 it was about how the "liaison nurse links ED to all the services out in the community". Both nurses acknowledged that liaison and coordination of services and care were roles expected of a nurse-led service.

Nurse 4 commented that the philosophy of St Vincent's Hospital that "care will be consistent with the values of compassion, justice, human dignity, excellence, unity, mercy, hospitality, and respect" (St Vincents, 2008a, p. 4), is a strength of the PECC service. "We see everyone who needs help, no one is turned away". The majority of presentations are of people who are homeless and hungry; they are offered appropriate care and very often leave after a meal and hot drink.

The consumer representative identified the uniqueness of the PECC facility as its strengths. "Based on short care stay, patient's immediate problems are dealt with. Excellent facility is the best in NSW, state of the art with no seclusion room; PECC food better than Caritas" [inpatient unit]. However, the consumer representative noted that in feedback from mental health consumer forums many consumers were unaware of the PECC service and its role. Those who knew the service shared a common understanding that the role was to provide additional beds to help with bed shortages in the inpatient unit. Comments the consumer representative had heard included; "People only have short stay and it seems to be pretty busy. The time I went down there was six people and quite a lot of activity. I thought it was ED patients not consumers".

The consumer representative emphasised the effectiveness of the service and suggested a way for PECC staff to promote the service. 
There is no doubt in my mind of the importance that the PECC service plays in the journey of people with mental health illness in the system. Even though we have highlighted several issues in this interview the issues mainly relate to systems issues, influenced by lack of resources not by lack of care from staff I have met and that if there was going to be reduction [staff] thru budget cuts it would be an area I would lobby vigorously not to be affected. I would like St Vincent's PECC service [to] be nominated for an award next year and will guide the application. I see it [PECC] as a specialist service, yes, it is effective.

\section{Weaknesses of the PECC Service}

Nurses commented on several issues that impacted on the delivery of care perceived as weaknesses of the PECC service. They included poor physical design and structural limitations of the unit:

The environment has no windows, no fresh air, no washing machine or laundry. Lounge looks like a waiting room. Just because it's a short stay unit, I think it shouldn't necessary look like a holding bay. Nurse 5

Three nurses described weaknesses as the indifferent attitude of some ED staff toward patients, poor clinical practice, lack of mental health experience of medical staff and nursing shortages. For Nurse 1 it was the "attitude toward patients that is what is needed to change"; the change needs to be from one that focuses "on bed occupancy, vacancies" to be more patient focused. Nurse 2 considered that there were areas for improvement and extending practice by both nurses and doctors.

Nursing practice is not good as it could be; short length of stay, observation than engagement, not using basic skills, should be running groups, education programmes or counselling sessions. Some registrars lack experience of [working with] junior doctors.

Nurse 3 however felt that a weakness of the service was work related stresses which resulted in "nursing staff high sick leave and the job being incredibly stressful". 
Dissatisfaction was expressed by several nurses with what they referred to as inappropriate admissions. These nurses considered that the admission criteria varied depending which registrar is on duty and the inexperience of junior doctors. Inappropriate admissions refer to those people who are admitted into PECC who do not fit the admission criteria. These include people who are drug seekers, malingerers and those hiding from the law. Another issue raised was that some patients often have inappropriate requests "they treat the place like a hotel, they keep asking for diazepam" (Nurse 6).

Frustration was expressed by some of the nurses interviewed with some ED staff is lack of understanding of PECC staff role in ED. The comments indicate that patients who have a history of mental illness and who are currently stable but in need of medical assistance are discriminated in terms of not receiving appropriate care. It was considered that some patients "who require medical assistance are triaged low priority" (Nurse 5) and are "are left in the waiting room" for the PECC team (Nurse 6). It was also raised that people who are intoxicated with either alcohol or drugs are often escorted into the assessment rooms which are allocated for mental health presentations and that they "are frequently left for PECC staff to deal with" (Nurse 7).

The consumer representative indicated that the lack of a service wide Information Booklet contributed to confusion among patients as to what, where and how appropriate services could be accessed was a definite weakness of the service.

My aim is to improve access to information and the people who are interviewed have provision for access to reference [to their illness or diagnosis]. My goal is that all MH services \& EDs have touch screen information screens available at their front doors and consumers can access them so they can be involved in their management of care and recovery process. 


\section{Changes to the PECC Service}

There was a shared view among nurses that PECC needed windows, courtyard, designated smoking outdoor area and a DVD player. Concern was expressed about the lack of laundry facilities for patient use "Patients sometimes come into PECC with soiled clothing, how we can care for them if their clothes are filthy?" (Nurse 8) was a cause of concern.

The consumer representative comments also supported the need for a courtyard and designated smoking area.

The number one complaint consumers brought forward to forums was the NSW Health Smoke Free Policy 2005. I believe it was implemented badly as it overlooked important recommendations pertaining to mental health consumers, that is, no provision of designated smoking areas for inpatients.

Nurses identified that some colleagues lacked knowledge about external services available to patients and to bridge the gap. Nurse 1 commented "I'd ensure staff visits the places we send patients e.g., Gorman House and Langton Place so they have greater knowledge of services therefore increase their confidence when planning follow up options. However, two nurses raised concerns about the lack of feedback and post discharge tracking mechanisms to inform staff about patients who have been referred on to other services "I'd improve feedback and post discharge processes just to know where our patients have gone to see if our interventions have been successful" (Nurse 7).

Frustration was expressed with the workload of the liaison role; nurses indicated that bed management and leadership were two responsibilities that interrupted effective work flow. Nurse 1 indicated that the "appointment of another CNC to provide clinical leadership to staff and support current the CNC would be a positive change" and "the extra CNC be responsible for bed management and patient flow" (Nurse 7). 
In contrast Nurse 8 viewed the bed management role as an "integral function of the liaison role". Liaison nurses are informed of available beds in local hospitals and plan patient transfer or repatriate them back to their catchments area. Furthermore the liaison nurse ensures timely patient flow in the ED reducing potential bed blocking.

Nurses felt that some junior medical staff lacked the confidence to work effectively and confidently across PECC and ED, and that this impacted on patients being reviewed/assessed in a timely fashion. Nurse 1 commented "Medical staff are not working efficiently and often move to next rotation too early" and Nurse 2 indicated that with "longer rotations and clinical direction, junior doctors would improve their assessment skills and improve patient length of stay in ED and PECC”.

Nurses indicated that they would like more education on topics that covered three areas of practice; clinical skills, therapeutic interventions and information about other services that impact on PECC specifically, Nurse 3 stated that she "would like medical nursing skills, more experience in drug and alcohol assessments and understanding about the Alcohol Withdrawal Scale”. Nurse 4 reported "Training on cognitive behaviour therapy, motivational interviewing skills and mindfulness training would be beneficial to PECC patients".

\section{Role of the liaison nurse}

Nurses described the diversity of the liaison role and had similar views how they would start their shift. Some tasks included; patient hand-over and logging on to the ED information system, reading patients notes, introduction to patient and initiating patient care. One nurse, however, indicated that a typical shift is one that is exclusive to ED. Furthermore, can be "volatile and stressful, high acuity with limited available beds" (Nurse 5). 


\section{Typical patient presentation and the work of the liaison nurse}

Nurses provided similar descriptions of a typical patient as a person who is intoxicated, male, has a history of alcohol and substance use, poor coping skills with little or no family support. He is aged between 25-45 years, in a dishevelled state, bought in by the police, hand cuffed, under Section 22 (NSW Mental Health Act 2007) with a request for a psychiatric assessment for suicidal ideation and thoughts of self harm. Reasons for initial police involvement varied although there are strong indications that this group of patients have underlying behavioural and relationship issues. One description was

Picked up committing minor illegal act and when arrested stated he was suicidal. Homeless guy, refused entry to all hostels for fighting, has nowhere to go to now feels suicidal. Argument with boyfriend who lives in a hostel, self referred to police. Nurse 5

Frustration was expressed about the management of patients identified in above group, and of the impact of this group on the service.

Both PECC and the ED nurses talked of being subjected to abuse, aggression, hostility, and sometimes violence. This raised the issue of safety of self and others; and appropriately managing complex behaviour. At times this required the patient to be sedated and monitored in one of the resuscitation cubicles normally used for major trauma. In these circumstances patients remain in the care of ED staff until their blood alcohol levels stabilised, sober and medically cleared. Occasionally, in these situations problems around patient management occur, especially when all resuscitation cubicles are occupied and ED nurses are busy. Nurse 6 expressed anxiety and concern in these circumstances; "I feel so guilty when ED busy, I want to help but don't have the skills".

There was a shared view among nurses about the admission process for the above presentation that is, inform hospital security; discuss situation with police; ensure legal papers correctly signed; inform ED nurse special assigned to observe patient and transfer patient from police van to assessment room. However, once the patient arrived into the 
assessment room nurses described varying methods of patient engagement which included offer of fluids or food; undertake baseline observations or initiating treatment.

In the comments about recent patients cared for, the following descriptions emerged. For Nurse 1 it was offering "food, fluids and clean clothes before initiating the assessment process" and Nurse 7 "Engaged with the patient to gather medical, psychiatric and social history". Nurse 8 was able to access vital information such as management plan and medical records from various hospital data-bases because "I knew the patient" while Nurse 2 "initiated the assessment process, baseline observations, did bloods and request urine specimen”. In contrast, Nurse 2 ascertained that the patient was homeless and was seeking a bed for the night. The patient was referred to the duty social worker to find suitable accommodation. Two nurses initiated rapid sedation process because of "patient, spitting, abusive and threatening harm to others. Combative, abusive and banging his head into the walls".

As part of the treatment process the nurses identified they had consulted several multidisciplinary clinicians and significant others known to the patient. They included the PECC medical team, PECC consultant, ED coordinator, CNC and social worker. Some talked of contacting other service providers for information, informed hospital security staff, patient's general practitioner and family, and informing triage nurse, ED nursespecial and police.

There was a shared understanding among nurses about the discharge planning of patients who are intoxicated and present with suicidal ideation. Nurse 5 sums up what many nurses said namely;

Patient had a sober review, not suicidal, offered Alcohol and Drug services, accommodation found, discharged with follow up appointment to community mental health services. Arranged overnight Acute Care Team to follow up and referred to Alcohol and Drug services. 
To better understand the liaison nurses work they were asked to describe what they considered was an easy or straight forward presentation and what they considered was difficult. Nurses generally indicated they found patients who live in the catchment area with identifiable mental illness and known to the services easiest to manage. One of the main reasons is accessibility to patient details and current clinical notes "Patients in this group have management plans, a case worker and notes are easily accessed" (Nurse 6), while Nurse 7 described "symptoms obvious, history available, previous files can be located; the management plan is usually straight forward".

Another reason is the willingness of teams across local services to participate in and discuss the management of local patients who require stabilisation of their illness. Nurse 8 indicated "These patients are brought in by the community team and usually fits the PECC admission criteria" and patients "present at a time when beds are available and community services are involved in the admission and discharge" (Nurse 1). While request for a PECC admission is usually discussed with PECC psychiatrist, registrar and bed manager, clinical management of these patients is maintained by the community psychiatry team and cared for by PECC nurses.

Nurses described patients who they find difficult in the ED as those diagnosed with Borderline Personality Disorder, narcissistic in nature, history of self harm and who have poor coping skills. Responses indicate that manipulation; unrealistic demands on staff and inconsistent behaviour patterns make it difficult for staff to form a therapeutic relationship with these patients. Frustration and anxiety also are expressed in nurses perceptions of the patient, Nurse 2 considered this group as "challenging, time consuming and demanding with no change in their behaviour". Nurse 3 stated that the "reason I find them hard as there is no early solutions and [they] are impulsive. They settle easily, but still require extraordinary input". For Nurse 4 some of these patients "constantly needed reassuring and validation of their feelings which can take up a lot of time. I feel I am always watching what I say as [they] are so sensitive and reactive”. 
Nurse 5 was more explicit and reported difficulty in managing patients with complex behaviours in critical situations. "I find hostile people more difficult than aggressive or violent individuals who are loud and abusive". The majority of nurses commented that ED was not an appropriate environment in which to manage challenging behaviour and Nurse 6 indicated “rapid sedation as a choice for managing such behaviour”.

\section{Skills and knowledge utilised in the liaison role}

The majority of nurses identified the advantages of using various communication skills and behaviour management techniques in an attempt to develop rapport with patients. Some nurses felt communication skills are the most important skill required in the liaison role. For Nurse 7 "Good communication, engagement skills, clear and direct, and still express an underlying attitude of care" were essential components of therapeutic intervention and "active listening skills essential to patient engagement" (Nurse 8). However, Nurse 1 used "humour, clinical experience and reflective practice" in the role. In contrast, Nurse 2 depended on clinical skills such as the "ability to perform rapid assessments; obtain patient history, identify risks, prevent escalation of behaviours, establish treatment and medication management plan" and at a different level Nurse 3 used "education, collaboration and liaison skills" when working on shifts with no medical staff on site. And another indicated that using clinical experience and communication skills contributed to patient flow in the ED.

Knowledge utilised in the liaison role were varied in description, Nurse 4 described previous experiences "from previous mental health roles and working with known patients is often used in the role". Nurse 5 stated education and resources strengthen knowledge base in practice "I use knowledge gathered from my study. I try to be evidenced based and use resources from the intranet frequently". The utilisation of clinical practice and confidence in the use of information technology were important features of knowledge for liaison nurses, Nurse 6 used "legal knowledge (NSW Mental Health Act, 2007), assessment skills, diagnostic, pharmacology, physiology and health and safety knowledge in their practice" and Nurse 7 used "mental health information systems and local knowledge of external services, e.g. Non Profit Organisations”. In 
contrast, Nurse 8 reported that the lack of knowledge in clinical skills and experience impacts on delivery of patient care "inconsistent level of experience and seniority of the liaison nurse and lack of physical clinical skills impacts on effectiveness of patient care and flow”.

\section{What works well and what could be improved in the liaison role?}

There was shared agreement that the liaison role works well because, it is inclusive of the ED team and respected by both teams. Nurse 2 described what most nurses said namely;

The liaison nurse works well in terms of integration and collaboration of patient care in the ED. Liaison nurse understands both services and have strong links to PECC. Liaison nurses are approachable and resourceful which was appreciated by both teams.

Two nurses indicated that liaison nurses are "effective communicators and have leadership skills". Nurse 3 maintains the liaison nurse links the services together by maintaining a "physical presence in ED, ensuring CNC, PECC nurses, Caritas, triage nurse, ED coordinator and medical teams are all involved in patient flow and decision making”. Even though some nurses were happy with the relationship with ED, Nurse 5 noted that the "relationship taken three years to develop". In contrast, others suggested the relationship remains strained "them and us relationship" (Nurse 6), and "maintains better relationship with small group of ED staff" (Nurse 7).

On the positive side, nurses reported that ED staff use the liaison nurse as a resource and provide leadership in the management of difficult patients. Nurse 8 described the relationship between both teams as "PECC and ED teams work well together". Nurse 1 stated that the "clinical reporting was done well" between PECC staff and liaison nurse worked well. This is described by Nurse 2 as the "liaison nurse provides a good handover. It's really impressive the way we work, morning liaison nurse will start a process and afternoon liaison nurse will complete it". 
Nurses felt that collaboration and forging partnerships with other teams and services was identified as strength of the role. Nurse 8 reported "collaboration is important because we provide a service that sits on a continuum of a patient's journey therefore we need to form relationships with others services for their recovery". Coordination, liaising and directing services in the ED was another strength identified by nurses. Nurse 3 reported that nurses;

Liaises directly to senior psychiatric medical staff, liaises with other services on behalf of ED, early intervention, assessment and treatment of each presentation, ability to direct appropriate treatment for each presentation.

Nurses' responses identified several aspects of clinical practice that could be implemented to improve the liaison role. Dissatisfaction was expressed with the brief orientation programme training period. Nurse 4 suggested "introducing longer induction period of training new staff" and Nurse 5 stated "new staff not confident to work in the ED within three weeks of appointment". One nurse indicated that the bed management role was stressful and wanted to "withdraw or reassign bed management role" (Nurse 6). One way suggested to alleviate the stress was to designate a full time a liaison nurse in the ED 24 hours, to spread the workload and improve patient flow at night (Nurse 7).

In contrast, frustration was expressed about rapid patient flow through ED especially when busy; Nurse 1 stated it was important to "inform doctors of unrealistic expectations of quick turnover of patients". Other issues expressed were the poor communication between clinicians and lack of skills of nurses. For Nurse 8 felt "lines of communication among staff required improvement" as did the "mental health knowledge of ED special nurses". Nurse 2 suggested that "PECC nurses should improve their medical knowledge".

The consumer representative suggested nurses be actively involved participating in consumer forums. "Nurses need to promote their role aggressively and participate in 
mental health forums. Introduce a liaison role summary in the mental health newsletter". On a positive side consumer representative added; "feedback from Mental Health Consumers Perceptions and Experiences of Services survey results were no verbal or written complaints about mental health treatment received in ED or PECC”. Nurse 8 added that the "identification of PECC nurses as part of the ED indicates that there is an integration of services in line with the national mental health plan”.

\section{The supports and structures that enable and that limit the liaison role}

There was a shared view from nurses that the role was successful because of the leadership style and support of the PECC CNC to nursing and medical teams. Responses indicated that having access to and ability to maintain open communication with the CNC was significant in the strength and success of the PECC service. They included; "CNC strong leadership skills. Good relationship and open communication with the CNC. CNC is readily available to staff" (Nurse 4 ).

The majority of nurses stated that effective communication skills featured highly in strengthening the role. Essentially, the ability to communicate to others at different levels was important especially when negotiating for beds and "building relationships with other services and building rapport with patients" (Nurse 5). Others indicated team and peer support and the fact all PECC nurses were experienced mental health nurses enabled the role to work well expressed as; "understanding skilled mental health team. PECC nurses have similar working backgrounds. We know how each works and work well together" (Nurse 7).

Nurses reported that experience in accessing health data-bases and various patient reporting data bases enabled the liaison nurse to work more efficiently, Nurse 3 expressed this as; "when nurses have learnt to access patient information data bases and service policies, helps patient flow to run smoother" and "easy access to on line clinical guidelines and policies is very helpful" (Nurse 4). Nurse 6 highlighted reasons for information systems training "training in understanding about how to access information 
systems, e.g. ED information systems, CHIME and intranet important because you need to know what's happening at a service, local and national level". While most PECC nurses reported they access information systems, a small number actually access clinical guidelines and organisational policies. However, the area of clinical supervision was mentioned as important to "support the liaison nurse" (Nurse 5).

In contrast, nurses reported issues that make the role difficult often occurred in ED, namely attitude and actions of some ED staff and Police to mental health patients. Concerns highlighted related to lack of empathy and poor communication skills of professionals because of inexperience dealing with people suffering from mental illness. Nurse 3 felt that "ED coordinators regard for mental health patients [was they were] not as important as medical patients. They find them at times unhelpful and often not supportive. Our patients need to be taken seriously”. Frustration was expressed by some nurses about the "Lack of understanding of mental illness from the ED staff and police" (Nurse 4) and Nurse 5 stated "Some ED staff bring patients to us to deal with because they too hard to manage”.

Issues of concern were expressed about the inexperience of nurse specials that monitor mental health patients in the ED. The majority of them were considered to have no mental health experience; they are employed by nursing agencies and vary in nursing experience. Nurse 3 considered that "ED nurse specials do more harm than good, shout at the patients and leave them unattended". In some cases patients have absconded without been assessed by the PECC team "Nurse Special saw the patient leave but didn't do anything or report it”. Language is another problem, for some agency nurses speak little English and communication is difficult.

Another issue raised is the level of some ED staff practices, Nurse 7 felt that "some ED staff does not follow proper admission protocols, inappropriate referrals were often made and inappropriate patients are left in the assessment rooms. What is implied here is that on some occasions intoxicated patients who are sedated are put in the assessment rooms and left without any discussion between teams having taken place. Many patients who fit 
this category do not have a mental health issue or history. Nurse 5 expressed similar concerns "we are given inappropriate referrals, usually those who need extensive medical input, for example, an elderly, confused dehydrated person”.

\section{The intersect between the liaison role with that of the ED and PECC roles}

There was a shared agreement among nurses that the liaison nurse intersects and involves the ED and PECC staff in clinical decision making regarding assessments, patient flow or bed access. The role also provides legal oversight in the application of NSW Mental Health Act 2007 and as a resource in behaviour management. Two nurses felt that good communication between liaison nurse and key ED staff significant in managing bed flow, expressed as "ED doctors consult us. Patient flow is managed by liaison nurse, that is, knowledge of where mental health beds are" (Nurse 8). While the liaison role plays a pivotal role in patient flow of mental health presentations in the ED, planning or outcome of patients seen is discussed with PECC CNC, ED coordinator and PECC medical team.

Nurse 1 described that the role intersects well with ED for several reasons;

Maintains a physical presence in ED from 07.00 - 22.00 and provides 24 hour phone consultation for ED staff. Furthermore, that the nurse is a resource for all mental health presentations assisting in assessment and risk formulation. Liaison nurses are ED's link to other hospitals, departments and psychiatric services.

In contrast, concern was expressed that the liaison nurse was held responsible for the high acuity by some ED staff "sometimes I feel that I am made to feel responsible when there are too many mental health patients in ED” (Nurse 2).

Inside knowledge and experience of working in PECC was a reason given why the liaison role intersected with PECC "it intersects very easily because we are one in the same team. Use PECC team as a valuable resource and to debrief. PECC nurses are very helpful when busy in ED; PECC is an option for placement" (Nurse 3). According to 
Nurse 4 it was an inappropriate use of PECC to relieve bed pressure in ED. "Sometimes patients are brought into PECC to free beds up in ED and the liaison nurse leaves them for us to deal with. Usually the paper work is incomplete and some patients not suitable for PECC”. The remaining comments provided insight into the inflexibility of inpatient services and ED staff lack of knowledge about the liaison role.

\section{Effectiveness of the liaison role}

There were various examples of how nurses described the effectiveness of the liaison role. Direct access to clients was seen as important because it "enables ED staff to attend to general emergency cases" (Nurse 1). However, for Nurse 2 increasing numbers of "mental health patients seen in ED was a measure of effectiveness". The provision of rapid response to intervention, care and treatment were other examples of effectiveness of the role. In contrast, frustration was expressed about the impact of bed blocking in ED whereby liaison nurses felt ineffective in their role "sometimes, due to bed block and individual circumstances we are less effective, but even then provide value by managing the situation" (Nurse 5). Furthermore, on the rare occasion where the liaison nurse is not available, ED staff has reported bed block and slower work flow.

\section{Role of the PECC nurse}

Nurses described the complexity of the PECC role and share similar views how they would start their shift. Some tasks included; patient handover, S4 and S8 (Schedule $4 \& 8$ drugs are listed as prescribed only medications or restrictive medications) drug count, allocation of patients, reading patients notes, introduction to patient and dispensing medications.

Prepare daily staff allocation report; participate in patient review with medical team; initiating patient therapy and goal setting; prepare patient for discharge and arrange follow up from other services; participate in patient admissions, linking patients to support services, seeking information from other mental services, reviewing daily patient risk assessment, meet with family, carers or external agencies, escort patient to clinical diagnostic 
tests (CT scan, X-ray or EEG), organise and escort patient transfer to their catchment area hospital or to local inpatient.

Two nurses however, noted the different roles between shifts and reported that "morning shifts is taken up with patient reviews and discharges" and "most admissions come in the afternoon shift". In contrast, another stated that the "night PECC role is more autonomous and involves providing clinical overview in the ED for mental health presentations". The night shift PECC nurse maintains a close clinical relationship with key ED staff and PECC registrar on call and is the key person who oversees police presentations during the night.

\section{Typical PECC Patient Presentation and the work of the PECC nurse}

Descriptions of a typical PECC patient provided by nurses were similar across each shift. Patients either self presented to ED or were referred by police, acute care teams, ambulance and ED hostels. The majority of admissions are transferred to PECC from ED however; some patients in the care of the community care team have direct entry at the discretion of the CNC and treating consultant. Reasons for admission include; brief stay, commencement of treatment and stabilisation of symptoms.

Patient presented to ED with suicidal ideation and/or threats of self harm with numerous stressors and social issues. They include poor family support, homeless, relationship issues and unemployed. The patient usually has a history of alcohol or substance abuse or gambling. Nurse 3

In contrast, one nurse described a typical presentation on night shift as; "patient not settled in ED, still in the acute phase not in crisis, resettled in PECC”.

There was a shared view of the work involved in the admission process. They included;

Orientate patient to PECC; searched property with patient for sharp objects and weapons; removed medications; offered PRN medication; assisted patient with self assessment forms; complete admission forms; formulate 
nursing plan and ensure risk assessment completed. Arranging an interpreter to be available for patient review; encouraged patient to ring a friend and family and provision of information on the Mental Health Act and Patient Rights, Nurse 5.

In contrast, two nurses commented that some patients on admission express to be left undisturbed and therefore patient engagement may not occur for some time "usually they have been on a binge, come in and sleep. Some patients are remorseful and sad, others demand to leave and others are referred on to appropriate services" (Nurse 2). Nurse 3 felt that the PECC nurse spends a lot of time post admission gathering information and background history about the patient from key persons. They include; "contacting specialist services, liaising with family, caregivers or contacting current services involved with the patient".

Nurses described morning shifts as busy and chaotic prompted by the volume of medical staff present and patients waiting to be reviewed in PECC and ED. Expressed as "mornings busy with doctor/patient reviews. Disorganised in the morning and more multidisciplinary staff around; more discharges and patient movement in the morning" (Nurse 6). Frustration was expressed about the waiting time of PECC patients for their daily psychiatric review by the medical team. Nurses reported that patient outcomes were dependent on how busy PECC doctors are in ED. "PECC team are often engaged in different ways depending on the situation in ED. Often we change priorities to meet the needs of PECC patients who are often left in limbo waiting decisions of review" (Nurse 1). Nurse 5 felt that "PECC patients are usually reviewed after ED patients, it's really annoying for some patients waiting to be discharged".

To summarise, the level of activity for PECC nurses during the morning shift is determined by length of patient reviews, medical staff meetings and mental health presentations in ED. However, there are more available support teams and services during the morning shift including the CNC. The variable activities identified above often 
impacts on the work of the afternoon PECC nurse whereby the morning nurse may start a task and afternoon nurse completes it.

Nurses reported afternoon activity in varying degrees. They included; "PM shift a lot quieter less team members to deal with e.g. doctors, and administration staff. Evening shift more relaxed; Lot less people in the office". Three nurses commented that there were "more admissions and discharges during this shift, and opportunity to spend with patients. Difficult time to get patients interviewed or reviewed by medical staff because of ED presentations". Another reported that the afternoon shift can be extra busy especially when the liaison nurse unavailable because of staff shortage.

Nurses described the night shift as quieter although one raised an issue of managing patients in the acute phase of illness; "Challenging if one or more patients are disturbed overnight as it is more evident than in the day how close the proximity the beds are when someone is awake, loud and restless" (Nurse 6).

Nurses provided similar descriptions of the PECC nurse activities involved in a typical patient discharge.

48 hours brief admission, mood improved, patient discharged with outpatient appointment to Green Card Clinic (Self Harm and Suicide Prevention Clinic). One patient had medications reviewed and discharge to care of friend. Accommodation in hostels was found for two patients and request for follow up by Acute Care team forwarded to community mental health services.

Patient presentation is not straight forward and different types of behaviours influences patient and nurse engagement which may or may not achieve the intended outcome. Four nurses identified patients who fit the criteria for admission into PECC as straight forward admissions. Patients in this group are perceived as; "wanting help and have insight into 
their condition with better outcomes and chances of recovery" (Nurse 7). Similarly, nurses generally felt confident working with patients with identifiable mental illness easiest presentations to manage. Reasons include, "easy to assess, symptoms are obvious; medication effective, results positive and transparent". Nurse 4 preferred "patients diagnosed with schizophrenia because they are what I know and I enjoy working with Axis 1 presentation”.

In contrast, nurses described the range of personality type presentations difficult presentations for various reasons. They included; "narcissist, histrionic, malingerers, borderline personality disorders and anti social types". Issues of concern were expressed when managing challenging behaviour in a small confined area and continual threats of self harm or violence if demands not met. Some nurses regarded these patients as highly manipulative and push boundaries. "PECC not suitable environment for behaviourally disturbed, abusive, hostile patient. They make threats to harm themselves if they don't get their way; difficult to control, time consumers" (Nurse 6).

Two others described patients with difficult behaviours as challenging and yet easy presentations to work with.

Patients with personality disorders while challenging, enjoyable and rewarding. Enjoy police presentation, have done a lot of assessments, comfortable making judgement calls, got a good understanding of legal requirements and autonomous practice.

Frustration was expressed caring for patients who are passive and unwilling to engage in solution focus therapy or work through issues as frustrating to help. Descriptions include; "malingerers and frequent flyers who are suicidal caused by drug and alcohol consumption" (Nurse 1). Nurse 5 commented on frustration over, "incomplete admission procedures and receiving direct admissions with incomplete collateral." The main factor was length of time taken in seeking information to complete assessment and admission process. 


\section{Skills and knowledge utilised in the PECC Role}

Nurses described a range of diverse skills which covered four areas of practice. They included communication, knowledge, clinical practice and leadership and were listed in order according to participant's preference. Comments included,

Experience in de escalation and negotiation techniques; therapeutic, counseling and building rapport. Uses humour, reflective practice and respect. Assessment skills mental health, physical, medical and risk assessment skills, writing and observation skills and medication management.

Nurse 4

Nurses described knowledge used in the PECC role in a variety of terms. They included knowledge of how to communicate, utilising a range of clinical skills, knowledge gained from experiences and systems information as valuable. These were expressed as;

PECC nurses direct communication skills and attitude of care. Familiar with working with the NSW Mental Health Act 2007. Utilises medication protocols and guidelines when using rapid sedation and the Alcohol Withdrawal Scale; Experience in mental health nursing, emergency nursing, life experiences, using intuition and bed management knowledge. Ability to access policies and procedure data bases, access to external services and resource. Nurse 6

\section{What works well and what could be improved in PECC}

Nurses identified strong cohesive team, the flat nursing management structure and supportive medical team as reasons why PECC works well. The tone of some responses suggests that nurses' were happy with the nurse led concept to lead the service. Nurse 5 expressed it as;

Good team and medical staff, we have no real hierarchy and generally like each other. I find not having a nurse unit manager beneficial because it shows a degree of respect for our expertise and self manage as a unit.

Nurse 6 felt that "the appointment; of a PECC consultant has improved patient flow". 
Nurses stated that improvement needed to be done to the PECC physical design to make the unit more patient and worker friendly. They included;

Need activity room for patients as they need to do something to lift their mood; Patients complain of having nothing to except watch television and read. Environment lacks natural light. Build outdoor area for patients. Nurse 3

\section{The supports and structures that enable and that limit the PECC role}

Nurses identified maintaining relationships with key personal enables the PECC role to function effectively. Each had a role to play in providing various services to offer patients for continuity of care while in PECC and post discharge. Nurse 6 sums up what many nurses said principally;

Multi disciplinary teams, ED staff, medical staff; CNC, after hours nurse managers and liaison nurse. The leadership style of the CNC. Good support from medical staff, social worker and drug and alcohol services. After hours nurse managers supportive of my role, willing to listen and ask advice.

Other supportive structures that assist PECC nurses in their role are the clear admission criterion and experienced specialist nurses. Nurse 2 felt that "it enables nurse to work autonomously and guards other services from dumping difficult patients in PECC”. In addition, Nurse 4 indicated that "clinical supervision would help nurses in their role and guard against burnout”.

Nurses identified how staff shortages and sick leave impacted on their daily performance which at times made the role difficult and exhausting. Frustration was expressed as;

Staff shortages and high sick leave impact on regular staff Very high absenteeism of staff. Nurses on light or restrictive duties also impacts on the staff, regular nurses end up doing three roles; in-charge, liaison and working with agency nurses. Not all nurses rotate shifts to include liaison role 
because they're on light duties. Greater work load for the rest of the team, higher stress.

The tone of comments suggests frustration about the potential for burnout when staff shortages do occur. There are expectations for nurses' to cover liaison role, in-charge PECC role, as well as patient flow and bed management roles. Furthermore, concern about utilisation of casual agency nurses who have no mental health experience often causes more work because of their lack of knowledge. "There have been shifts when two agency nurses run PECC (Nurse 3). In contrast, Nurse 5 felt that issues around unplanned patient discharge from PECC to accommodate patient flow from ED made the role difficult "length of stay may be cut short to create beds and therefore patient needs not met”.

Four nurses expressed concern about the lack of accommodation in hostels or refuges for patients in NSW. However, other issues often impact on nurses who are attempting to find temporary accommodation for patients. While every effort is made to ensure patients have accommodation on discharge there have been rare instances where they are discharged back to the streets. "Patients are refused accommodation because of known unacceptable behaviour or hostel full. Patients have declined offer of accommodation and returned to the streets" (Nurse 4). The consumer representative identified that the lack of data pertaining to identifying the actual numbers of NSW population who are homeless suffering with mental illness as one of the gaps in service provision.

\section{The intersect between the PECC role with that of the ED and liaison role}

Nurses indicated that the role intersects with ED staff at different levels. Nurse 1 felt that the PECC nurse "supports the liaison nurse in patient flow and acts as a resource person. Some ED nurses have PECC nursing experience. ED staff integral part of the assessment process at night and PECC nurses relies on them on night shift". Two nurses described opposing views and reported that the role did not intersect at all with ED staff. Another indicated the ED staff lack of understanding about PECC service provision and admission 
criteria “Doesn't intersect as much as it should; Lack of understanding of PECC role. When there are many mental health patients in ED, staff don't understand why patients not for PECC” (Nurse 5).

Nurses reported that the liaison nurse keep PECC nurses informed about ED activity and potential PECC admissions. Both roles include patient hand over, care planning and outcome goals when patient arrives into PECC. "Both roles are done by one nurse on night shift. Roles are rotated daily. Continuity of patient care, a nurse may have assessed the patient as liaison nurse then care for them next day as a PECC nurse" (Nurse 7).

\section{Effectiveness of the PECC role}

Nurses commented that the PECC role is effective in different areas and for different reasons. Comments included;

Provide short term care. PECC referrals to other services support patients to stay in the community. Access to specialist services; avoids unnecessary inpatient admissions; Staff able to broker appropriate services or placement for patients and have 24 to 48 hour framework to provide care. Staff skilled in assessments; PECC has defined admission criteria which patients can be not admitted, e.g. violent person. Good patient feedback. Provide early intervention. Nurse 8

In contrast, two nurses raised issues that impeded on the role's effectiveness due to lack of accommodation and lack of patient tracking among some general practitioners. "Hindered by lack of long stay hostels, supported accommodation and rehabilitation units. General practitioners who over prescribe benzodiazepam drugs to their patient who ultimately doctor shops for more drugs. The frustration in these cases refers to length of time, resources, expenses, in terms of sending referrals, toll calls, specialist services input, knowing that the patient will be referred back mental health services. A nurse also commented that it is unclear how the PECC service impacted on suicide prevention. 


\section{Supervision and support to work in the PECC and the Liaison role}

Some nurses identified topics they needed advice on were ones that primarily are the source of some mental health problem for patients. They included; drug and alcohol issues, pharmacology and complex medical problems. Another reported that they often sought advice on management of complex behaviours. Nurse 6 commented about the "need for and use of reflective practice". Others reported discussing the following topics at supervision;

Way I have handled difficult and risky situations. Discuss how to manage complex cases and it's good to debrief. Drug and alcohol issues and want to know how to manage challenging behaviour and need assistance with reflective practice. No typical areas use clinical supervision to discuss areas of practice and use colleagues to reflect on practice and learn from their experiences. Advice needed all times when it stops look for the information. Nurse 8

Nurses identified various people and methods of clinical supervision. They included; "PECC CNC, drug and alcohol CNC and peers; clinical supervisor and mother (mental health nurse); uses intranet, medical team, journals and evidenced based studies". Three nurses receive group clinical supervision. Two others initially participated in group supervision but found it unhelpful and said it did not meet their needs. Four nurses receive 1:1 clinical supervision in varying forms. They include; utilising peer debrief; personal psychotherapy; clinical supervisor and phone supervision from a senior staff member. Receiving regular clinical supervision is a standard requirement for all PECC nurses.

In conclusion, the nurses and consumer representative provided invaluable information concerning the work of the PECC service. While this information is important for this research Nurse 6 also said "I have found this to be a good opportunity to reflect on what we do well and what we need to improve, thank you. The following chapter discusses these findings. 


\section{Chapter 6: Discussion}

\section{Introduction}

The process evaluation was designed to examine the activities of the Psychiatric Emergency Care Centre (PECC) service at St Vincent's Hospital in Australia from November 2005 to December 2008 and its impact on key services and groups. The findings presented in Chapters 3 and 5 described from an insider's lens how the service worked and include an overview of patient throughput processes. Key strengths and weaknesses were identified as is the focus of evaluation research and this chapter discusses the issues raised and offers implications and recommendations to enhance the service and for further research. This is the first evaluation undertaken on a nurse-led PECC service in New South Wales (NSW). Frank et al.'s (2005) earlier work identified that the PECC model of care provided direct access to specialised mental health staff, reduced access block and early mental health responsibility for patients. This work both confirms some of Frank et al.'s findings but importantly adds to the understanding of PECC services by including the perspectives of both nurses and consumers who have been working in and engaged with the service.

The findings indicate that the PECC service has been successful in meeting its purposes to provide rapid assessment, treatment and access to specialist care for mental health patients. Most notably has been the impact on improved patient flow and reducing length of patient stay in the Emergency Department (ED) (Garling, 2008). There is a shared agreement among senior mental health and ED clinicians that the PECC model of care is delivering services as planned (Fulde, Director Emergency Department, St Vincents, Personal communication, 2009). This research confirmed that while consumers have high levels of satisfaction with care provided (St Vincents, 2009); there are ways the service can be improved.

The discussion highlights six general themes which summarise the findings. These are identified under the following headings: PECC as an integrated model of emergency 
mental health service; demand for treatment and support; role clarity and challenges; quality and service development. The chapter concludes with a reflection on the methodology used and a summary of potential future research possibilities.

\section{PECC as an integrated model of emergency mental health service}

This evaluation described two services - PECC ED liaison service and, the PECC short stay service for people who present with an emergency mental health issue, are managed at St Vincent's Hospital. Health practitioners within these services work together which results in and initiate patient flow between the services. The two components of the PECC service are similar and integral to one another in that they assess, oversee or refer people for treatment who have presented with emergency psychiatric needs. The service is run by a multidisciplinary team, predominately registered nurses who are supported by medical practitioners and social workers. Two important positions in this integrated psychiatric emergency management are held by nurses; the short stay nurse commonly referred to as the PECC nurse and the PECC liaison nurse commonly referred to as the ED liaison nurse.

As part of an integrated service, people access the PECC service either directly (if referred by community teams), via the emergency department or on referral from other mental health services or the police. The nurses lead the assessment of the large number of people presenting to the ED and continue with the care and treatment in the PECC service. The PECC service attends to the smaller number of people who are likely to respond to concentrated therapeutic intervention over a short time. This service has an advantage of the nurses being integral as the first point of contact in the management planning and integration of services. Availability on site 24 hours a day with the ability to call on selected specialty services both internally and within the community means that an integrated service can work together in formulating a management and discharge plan for the people assessed. 
The findings of patient flow in and out of PECC indicated that the service interacts well with other services, with people being discharged to at least nine mental health services across the region. PECC nurses play a key role in this inter-agency collaboration by facilitating patient flow through the ED and PECC. PECC nurses liaise with other services for patient placement ensuring patient flow to reduce waiting times in ED and to minimise or prevent access blocks for patients. The service also has a key role in the provision of direct access to specialist services for mental health patients and links ED to other services to support the treatment and management of people with mental health presentations.

The findings highlight how the service promotes inter-agency collaboration and is pivotal to ongoing care and the prevention of relapse of illness. PECC also provides direct contact to other community services providers and social services for those people who have social in addition to mental health needs. This particular group of patients could be managed in the community but for social reasons this is not always possible. The majority are homeless, and usually have addiction and financial problems. In this situation the social worker, PECC and if appropriate, acute care teams are be involved the decision making while the person is still centred in the emergency environment.

\section{Demand for treatment}

Table 1 shows that between 2005 and 2008 there was a significant increase of mental health presentations to the ED of $43.19 \%$ and yet PECC admissions remained fairly stable. Reasons for these differences in demand included the previously identified increase in the numbers of intoxicated patients presenting to ED. Intoxicated patients are generally discharged back to the community or referred to alcohol and drug services for detoxification from ED. What was apparent from the interviews with nurses was the collaborative way the PECC and ED nurses worked together to treat and manage the healthcare needs of these patients in the ED. The ED nurses overseeing any physical health matters, the PECC liaison nurse and PECC short stay nurse overseeing mental health matters. 
Another reason for the difference between mental health presentation and PECC admission is that many of the mental health patients presenting to the ED have been known to staff and already have accessible management plans that direct ED staff actions so that patients previous history can be utilised to manage their discharge, or where sufficiently transferred to the inpatient unit for appropriate treatment. A further reason that the PECC admissions have remained stable, most likely reflects the small size of the PECC unit, with only six beds there are not options for overload. Unfortunately statistics are not available to identify how often ED staff need to make alternative plans for patients because the PECC beds are fully occupied. It is possible that some of these increased presentations were transferred to other organisations and further research is needed to establish how often this occurs.

Similarly, patients who present with behavioural problems, drug seeking or who have no obvious acute mental health issues are discharged from ED following an integrated approach to management between ED, PECC and social work teams. However, the interview findings confirm that there are a group of patients who on presentation are acutely unwell yet are able to stabilise very quickly. The impact of these patients in ED has considerable implications for ED, PECC and the organisation. ED and PECC will continue to have a role to manage these patients while seeking accommodation for them. The duration of stay in the ED can affect the length of stay in the department and delay patient flow. However, as earlier stated these patients do not fit the admission criteria into PECC and some medical staff will insist in admission or patient to remain in ED until accommodation is found.

As in most health areas personal perception of moral and ethical issues by staff affect whether a person is admitted or discharged. While there are clear guidelines as to who can be admitted to PECC it was apparent that people who did not meet the criteria were still referred to the service. The interview findings indicated that "inappropriate patients" were referred and these were people that nurses referred to as having complex and challenging behaviours. Often PECC and ED nurses were subjected to abuse and aggression by these patients. Follow through on why inappropriate referrals occurred was outside the scope of this evaluation however it is recommended that the service identify who and why patients 
who are "inappropriate" to their service are referred there. This would then require further work with ED management to ensure that clearer guidelines are created and orientation and education for junior ED doctors is developed.

Another compounding factor that adds to aggression and hostility is patients' demand to go out for a cigarette and, since the no smoking policy was introduced staff strive to uphold the promotion of no smoking on campus. There are provisions to offer patients' nicotine patches which can result in increasing the patient's frustration and ultimately a patient given sedation due to increased aggression. Implications involve cost of sedation, patient monitored in the resuscitation cubicle and longer length of stay. The implications for nurses are safety issues which implicates the organisation. While providing safe smoking areas is complex especially in a short stay emergency environment the ability to change lifestyle habits is not a short term fix especially when addiction or mental health issues impact. Safe supervised alternative smoking areas may help reduce the need for sedation however cost benefit analysis would need to be considered if seeking an alternative.

Importantly this study highlighted concern regarding the group of patients presenting with social and mental health needs in relation to the lack of intercity accommodation, hostels or emergency boarding services for homeless patients in the Sydney region. Where possible the PECC and liaison nurses will collaborate with other services, family and/or carers to coordinate options of care for these patients. Consumers groups have raised such issues about the lack of housing and emergency accommodation (St Vincents, 2009) however; this evaluation indicates this poses dilemmas for the health service in that people who are stable enough to be discharged need to be housed short term. Unfortunately statistical evidence on repeat presentation for those who are homeless has not yet been kept and a recommendation would be to commence collection of this data to quantify the size of this problem for the PECC service and for the service to work alongside management, consumer groups and social agencies to identify solutions should a problem be realised. 


\section{Role clarity and challenges}

The description by nurses of their perceptions of their role in ED and PECC and those of the consumer confirms that PECC nurses often work in a busy, highly stressful environment and assume extensive responsibilities and management duties within their roles. However, there is also evidence that some ED nurses and key personnel are unclear of the role of the PECC ED liaison and PECC short stay nurse. The implications of not knowing about the PECC service is that other staff can expect more from PECC nurses than they are able to deliver on. This lack of knowledge has an impact on PECC nurses role in the ED. The purpose of the role is to provide assessments and access to patients with mental health issues with or without medical problems. However, some ED staff do not understand that patients who have behavioural problems and older persons with dementia fall outside the PECC nurses jurisdiction. The implications are that the patient is left to become the responsibility of PECC resulting in both communication and management issues. To address this issue PECC nurses are encouraged to provide inservice training to ED and other services to raise aware of PECC patient criteria and develop strategies with ED staff in formulating a collaborative approach to manage these patients.

Psychiatric emergency care nursing is an area of practice that requires high levels of responsibilities which includes decision making. The findings indicate that the liaison role involves negotiating, organising and planning before addressing decisions about patient flow and bed management or directing patient care in the ED. Nurses identified that decision-making is complicated by indirect acts of stigma and discrimination from other professionals and working with inexperienced agency nurses. For example, patients are escorted to sit outside of an occupied assessment rooms where privacy and confidentiality are compromised. Furthermore, there have been occasions when inexperienced nurse have allowed high risk patients to leave ED without being assessed. The need for highly skilled mental health nurses has been noted as a fundamental requirement for the liaison role with excellent interpersonal communication skills and who can clearly articulate their role to other ED workers. 
When working in the PECC unit nurses identified high levels of responsibilities in the management of the unit and staffing issues. The interviews confirmed that working in either of the PECC role is stressful when it is associated with staff shortages. These are made more difficult when occurrences of staff working on light duties for long periods of time exists, and where agency nurses inexperienced in mental health nursing are employed to fill gaps. The mental health management need to address this because nurses that are on sick leave or on reduced hours long term as well as the use of inexperienced nurses pose safety risks and add stress for existing staff compounding problems.

Associated with reduced staffing levels the findings identified that PECC nurses were sometimes expected to simultaneously undertake the PECC in charge and liaison roles. The impact of having to fulfil both roles is that it is personally exhausting for the nurses. In these situations some nurses with no or little mental health nursing experience have been utilised to cover PECC nurse shortages. This means that the liaison nurse may spend a greater proportion of their shift supervising these nurses as well as providing clinical support in ED. The implications of such an arrangement could result in decreased quality of care to patients and increased risk of safety to inexperience staff.

The evaluation also highlighted recruitment issues. While it is apparent that nurses are recruited on the basis of skill mix, experience and leadership skills, finding the right applicant who can readily work effectively in the PECC short stay service and in ED liaison role can take time. In the interviews the nurses raised questions about how staff were actually recruited and questioned the level of advertising done. In the instances where agency or casual nurses have applied for positions, permanent staff either initiated the process or had input in the decision-making of their appointment. To enable a more strategic and effective recruitment process for vacant positions the PECC nurses feel they should work with management about their recruitment / advertising strategy and review current recruitment procedures.

On a positive note a common factor that nurses appreciated about their role was their freedom for autonomous practice and their interface with multidisciplinary and other 
mental health teams. Some nurses, nevertheless, preferred to be directed by the medical team. This raises issues of uncertainty about their skills and a definite need for establishment of further in-service development to raise self esteem and to develop skills to a level expected of the unique role.

While more than half of the PECC nurses were confident in their roles, others expressed less confidence. Those who were more confident had significant experience in mental health nursing. Three nurses also had significant experience in other nursing specialities. An important finding was the marked variability of skills that PECC nurses had and their views about their lack of confidence in overseeing and providing care for patients with behavioural, alcohol and substance intoxication or who presented to ED having self harmed. Nurses considered they should be able to undertake physical and medical assessments, alcohol and drug assessments, and have the requisite clinical skills to assist the assessment process. The interview findings confirm that some PECC nurses lack experience and seniority and clinical skills which have impacted on the effectiveness of patient care and patient flow. Accordingly, an outcome of this would be inappropriate admissions into PECC. To address this issue it is recommended that the orientation period of new nurses be extended to 12 weeks and nurses generally have increased access to formal study to raise their skill level in clinical assessment and management. In addition it became clear that there is a need to ensure PECC nurses complete St Vincent's ED clinical education / training programme.

Another issue raised was the lack of understanding of the PECC service and its purpose in the provision of care by many consumers and members of the community. To address this lack of awareness information material about PECC services needs to be made readily available for consumer groups, patients, families and care-givers. This involves the development of a strategic marketing campaign which would need to be addressed by management. Nurses make those entering the service aware of the purpose and where appropriate family members and support people, however further information in the form of pamphlets which are clearly visible would be advantageous and supportive to staff. 
The multidisciplinary team also impacted on the work of the PECC nurses. The nurses found the inexperience of some junior doctors and registrars in managing psychiatric emergency care contributed to difficulties in the PECC and ED service. Inexperience of health professionals in the ED is not unique and other authors have identified that this is a major issue (Thompson, 2005). Lack of experience and knowledge of health professionals increases the potential of adverse implications for patients which includes delay in assessment or inappropriate treatment (Thompson). Poor assessment can contribute to patient's lengthy stay in ED and inappropriate PECC admissions. An evaluation of junior doctors' ability to manage mental health emergencies needs to be further investigated.

The interview findings show that depending on which role a nurse undertakes different communication skills are used. The results reflect that PECC nurses are effective communicators which are skills essential to their practice. Active listening skills, engagement and humour were identified as important skills for patient engagement. Education, collaboration and liaison skills were skills that nurses used when working autonomously without clinical support. A significant finding was that good communication skills and clinical confidence contributed to best patient flow in ED. The finding highlights that PECC nurses have excellent communication skills, and are confident and competent clinicians.

A significant finding is that some nurses have post-graduate qualifications while others do not. Evidence of ongoing education is a requirement the PECC nurse's job description and clinical nurse specialists must provide annual in-service training / education to staff to maintain their title. The impact of these findings is that there is a professional competence issue with a real need for some ongoing education for nurses not engaged in study. The mental health management team needs to develop a workforce development strategy to include education that is funded and supported by the organisation. The impact of such education should lead to higher qualifications, strengthen the workforce and encourage staff retention. 


\section{Quality and Service Development}

This evaluation has identified that PECC is part of an integrated service which promotes a multidisciplinary approach to health care led by nurses. In line with the concept of nurseled service, St Vincents PECC service is staffed by senior nurses with some who are engaged in post-graduate studies. These nurses are recognised as experts in their clinical speciality, for example, early intervention and drug and alcohol. PECC nurses are engaged in decision making concerning their patients and participate in service development and service delivery.

There were positive results about the PECC service and delivery of care by nurses and doctors. In particular, their caring approaches when dealing with patients, rapid assessment and access to treatment and uniqueness of PECC services. The interview findings show that mental health consumer feedback indicates consumers were happy with the concept of short stay and provision of short term treatment and the high impact of care and resources. The evaluation has not looked at specific health outcomes, evaluating the effectiveness from this perspective is important. The evaluation indicates that variables to include in any future outcome study concern change in mental health status during the PECC stay; rates of representation and rates of suicide.

The findings also indicate that PECC nurses need to be involved in participating in consumers' forums and groups. Consumers indicated that it was important for service development and recognition. It provides opportunities for PECC nurses to keep up with current trends of consumer expectations in service provision. Involvement with consumer groups strengthens partnerships in the involvement of patient care and monitoring quality of services.

A quality service is a service that is consumer responsive and, the nurses raised issues about the condition of patients' clothing on presentation and that these often needed washing but lack of laundry facilities precluded clean clothes. What is often overlooked is that nursing people who are socially isolated means that clothes can be a strangely 
affiliated personal possession and hospital gowns do not fit within their life patterns therefore attempting to force that move is likely to exacerbate existing health issues. There is a special need here to assist them in their clothing especially when patients in PECC are mostly dressed in day clothes. Close proximity to other patient within PECC also makes it essential that facilities are made available not only for the patient concerned but also for other patients who are affected by the soiled clothing. To address this issue the mental health services management team needs to provide funds and cover costs in implementing a laundry with washing machine and dryer or identify an existing facility close to PECC that could be utilised. Another option would be to increase a stock pile of donated clothes in ED to replace soiled ones.

The interview findings also highlight issues around unplanned discharges to accommodate patient flow in ED. Nurses described that in these situations patients did not have their needs met and were discharged before or in the middle of their treatment. This was an unanticipated finding and the impact for clinical practice means that the patient care is left in limbo and can lead to nurse's frustration in not being able to provide continuity in treatment and support. A major concern is that the patient may not be fit for discharge but nurses reported that they sometimes felt pressured instigating discharge. While PECC aims to both avoid unnecessary inpatient admissions and premature discharge into the community (St Vincents, 2008a) there was inconsistency in application. Some PECC nurses accept the need and decision to discharge the patient prematurely however others question this. This means that not only are patients receiving inconsistent messages and service but that the policy is not being managed. It is essential that further discussion occurs within the service so that the pressure of seeking beds does not to block patient flow in ED and that nurses and doctors do not miss the needs of the patients in their care. Consumers identified (St Vincents, 2009) feelings of vulnerability and powerlessness in the face of illness and premature discharge can exacerbate their symptoms. Such discussion needs to explore the repercussions of an adverse outcome for the patient, while balancing the need to attend to the purpose of PECC that is to ensure accessible patient flow from ED to the community or other appropriate services. 
A quality service ensures that care is delivered in a culturally sensitive environment. The aim of PECC staff is to provide patients with care that is close to their cultural background. PECC nurses coordinate interpreters for patients with limited understanding of the English language. While cultural practices are not the focus of this evaluation it does impact on a patient's length of stay and time of recovery. St Vincent's hospital is situated in the inner city and many patients who are seen in ED and admitted to PECC are from the range of different cultures that exist within large cities. Therefore nurses must know how to access government agencies, consulates and emigration services for information. Having readily available resources would ensure good time management and efficiency of networking.

The evaluation indicates PECC provides a safe and protective environment for patients who are depressed, suicidal, at risk of harming themselves and others, nurses also deal with people in crisis. Included are patients with a mental health problem who need medical attention and those who have relapsed but do not require long term stay. Accordingly, risk assessments are vital in ensuring the safety of patients who are admitted into PECC. Patients who are allocated a high risk category are prioritised for transfer to the inpatient unit (St Vincents, 2008a).

\section{Methodological Reflections}

This study utilised evaluation as a method to describe the service development, organisation and model of care of a PECC service within which I work. No existing evaluation was available to describe who and why people use the service or the PECC nurses activities and responsibilities or effectiveness of this model of care. As a beginning researcher the impact of time related to ethical approval, interviews for those already working long hours, the technology of recording and being intimately involved with the service made this research challenging. Identifying issues through evaluation study does not necessarily mean that changes can or will be made and often raises more questions than answers. Certainly a number of questions have been raised through this study and need for further investigation has been able to be identified. The method of evaluation has allowed evidence to be placed on the table for consideration and while limited to one 
environment, one place in time and a very small sample of opinion it is hoped that insight will be gained and improvements made to a unique way of supporting those with acute mental health problems.

\section{Implications and recommendations}

Throughout this chapter several implications have been identified for the service to be and remain effective. Staffing issues had a high profile in the feedback from participants. Without a highly experienced team and good understanding between the multidisciplinary team there is risk of misdiagnosis and people being discharged or admitted inappropriately. This is also related to ongoing professional development especially where there are areas such as addiction, behavioural issue and dementia which often fall through the cracks between mental health and medical issues. The implication of poor accommodation resources in the area means that there is unidentified risk associated with early discharge and this has implications for the future if the increase in presentations persists.

Recommendations identified included; increased staff development for the multidisciplinary team; instigating data collection for the number of patients that are referred to other organisations when PECC is full; development of policies in consultation with staff that result in consistency of referral to PECC; better staffing policies and recruitment that is aligned with staff expertise, and facilities for provision of clean clothes for patients.

In closing, this chapter has shown that the PECC service has fulfilled its role in ensuring rapid access to specialist assessment and treatment for patients with mental health problems. It maintains a close liaison and working relationship with ED and inpatient unit staff. PECC provides a safe environment for patients through a short stay admission thereby reducing unnecessary admissions to the inpatient unit. PECC has assisted in reducing patient length of stay in ED and assisted in improving patient flow by accepting early responsibility for mental health patients in ED. It is hoped that this evaluative study 
will provide knowledge about the PECC service to those for whom the model of care is new and also a way to progress this innovative model of care within our local service. 
Appendix 1 Example of the framework to review literature included in the evaluation:-

\begin{tabular}{|c|c|c|c|c|c|}
\hline $\begin{array}{l}\text { Author(s) Year } \\
\text { Country Model }\end{array}$ & $\begin{array}{l}\text { Aim of research } \\
\text { Research design }\end{array}$ & $\begin{array}{l}\text { Findings } \\
\text { Staffing }\end{array}$ & $\begin{array}{c}\text { Findings } \\
\text { Patient \& Outcomes }\end{array}$ & $\begin{array}{c}\text { Findings } \\
\text { Service Issues }\end{array}$ & Comments \\
\hline $\begin{array}{l}\text { Frank.R, Fawcett.L, } \\
\text { Emmerson,B (2005) } \\
\text { Australian Psychiatry Vol } \\
\text { 13, No 3. } 2005\end{array}$ & $\begin{array}{l}\text { Describes service development } 1^{\text {st }} \\
\text { Australian PEC } \\
\text { Operational model }\end{array}$ & $\begin{array}{l}\text { Specialised MH staff -- } \\
\text { potential staff burnout } \\
\text { problems with } \\
\text { recruitment \& } \\
\text { retention, } \\
\text { PEC part of Acute Care } \\
\text { Team } \\
\text { Staff rotate across sites } \\
2 \text { P/T psychiatrist } \\
3 \text { rostered shifts RMO's } \\
1 \text { CNC } \\
13.4 \text { clinical \& R/Ns }\end{array}$ & $\begin{array}{l}72,000 \text { presentations to ED } \\
\text { - yearly. } \\
\text { High acuity } \\
\text { Direct access to specialist } \\
\text { care } \\
\text { PEC staff take early } \\
\text { responsibility of patient } \\
\text { Reduced access block in } \\
\text { ED }\end{array}$ & $\begin{array}{l}\text { Multiple referral sources } \\
\text { Tertiary General ED } \\
\text { Expensive } \$ 1.4 \mathrm{~m} \text { yearly to } \\
\text { staff } \\
\text { best for }>500 \text { beds } \\
\text { patient increase from } 4400 \\
-1994 \text { to } 7200-2004\end{array}$ & $\begin{array}{l}\text { Model of care used in NSW } \\
\text { \& WA } \\
4 \text { beds, co-located ED, } \\
\text { opened } 1983 \\
\text { model accepted by ED staff } \\
\text { ED staff do not retain } \\
\text { assessment skills } \\
\text { Good history of } 3 \text { models of } \\
\text { emergency psychiatric care } \\
\text { in ED } \sqrt{ } \\
\text { Good service description } \sqrt{ } \\
\text { USE }\end{array}$ \\
\hline $\begin{array}{l}\text { Wand, T. White, K. } \\
\text { The Royal Australian and } \\
\text { New Zealand College of } \\
\text { Psychiatrists, } 2007 \text { p. } 784 \text { - } \\
791\end{array}$ & $\begin{array}{l}\text { Examined models of mental health } \\
\text { delivery in ED } \\
\text { Descriptive } \\
\text { Literature review medical \& } \\
\text { nursing literature 1990-2007 } \\
\text { Identified } 3 \text { MHL models } \\
\text { implemented to assist EDs } \\
\text { - } \quad \text { (a) Consultation liaison } \\
\text { - } \quad \text { (b) Psychiatric } \\
\text { emergency centres (B) } \\
\text { - (c) MHLN'S }\end{array}$ & $\begin{array}{l}\text { Mental health liaison } \\
\text { nurse role positive } \\
\text { outcomes in ED } \\
\text { Role accepted by } \\
\text { patients \& ED staff } \\
\text { MH nurse practitioner } \\
\text { role alternative }\end{array}$ & $\begin{array}{l}\text { Reduced waiting times } \\
\text { Efficient -therapeutic } \\
\text { intervention } \\
-\quad \text { Coordination of care } \\
-\quad \text { Patient follow up }\end{array}$ & $\begin{array}{l}\text { (c) MHNL role cost } \\
\text { effective approach } \\
\text { - } \quad \text { Long delays waiting } \\
\text { for assessment \& } \\
\text { discharge } \\
\text { - } \begin{array}{l}\text { High cost to maintain } \\
\text { separate facility }\end{array}\end{array}$ & $\begin{array}{l}\text { Further research required } \\
\text { into all methods of MH } \\
\text { service delivery in ED } \sqrt{ } \\
\text { In-depth socio-political } \\
\text { discussion } \sqrt{ } \\
\text { Strong balanced debate on } \\
3 \text { models } \sqrt{ } \\
\text { Future direction for MHN } \\
\text { practitioner role proposed } \\
\text { USE }\end{array}$ \\
\hline
\end{tabular}




\section{Appendix 2}

VICTORIA UNIVERSITY OF WELLINGTON

Te Whare Wananga o te Upoko o te Ika a Maui
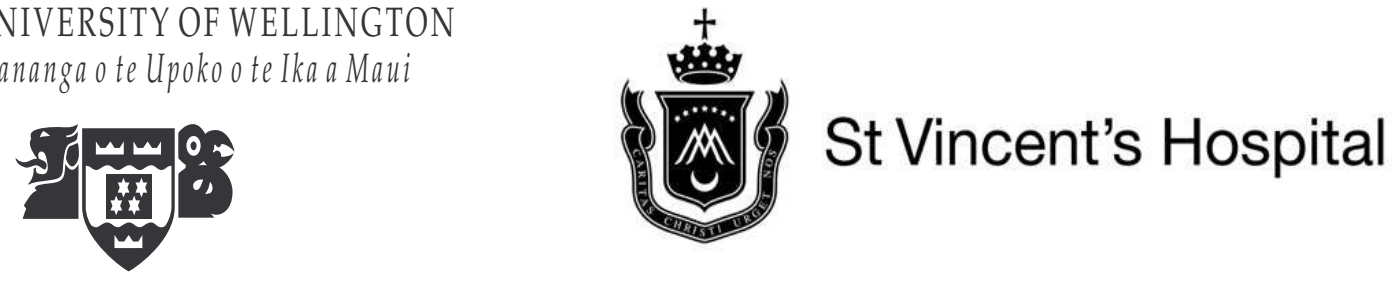

PARTICIPANT INFORMATION FORM

\section{An Evaluation of the Psychiatric Emergency Care Centre St Vincent's Hospital, New South Wales}

\section{Invitation}

You are invited to participate in a research study to evaluate the Psychiatric Emergency Care Centre (PECC) service.

The study is being conducted by Caroline Koia, Clinical Nurse Specialist, PECC, St Vincent's Hospital, New South Wales (NSW). It is supervised by Dr Katherine Nelson, Senior Lecturer in Nursing, Graduate School of Nursing, and Midwifery \& Health Victoria University of Wellington.

The study will form the basis of a thesis, which will be submitted for examination to Victoria University of Wellington, New Zealand.

Before you decide whether or not you wish to participate in this study, it is important for you to understand why the research is being done and what it will involve. Please take the time to read the following information carefully and discuss it with others if you wish.

1. 'What is the purpose of this study?'

The purpose is to describe how the PECC service operates, identify what works well and what can be improved and to inform ongoing development.

2. 'Why have I been invited to participate in this study?'

You are eligible to participate in this study because of your role in the programme.

3. 'What if I don't want to take part in this study or if I want to withdraw later?' 
Participation in this study is voluntary. It is completely up to you whether or not you participate.

If you wish to withdraw from the study once it has started, you can do so up to two weeks after the interview without having to give a reason, at which point your interview data will be destroyed.

\section{4. 'What does this study involve?'}

If you agree to participate in this study, you will be asked to sign the Participant Consent Form which indicates your agreement to be interviewed. The interview will take place at a time and place mutually agreed and will last approximately one hour.

\section{5. 'How is this study being paid for?'}

This study is being funded by the Psychiatric Emergency Care Centre (PECC); a grant from Victoria University of Wellington will also be applied for.

\section{6. 'Are there risks to me in taking part in this study?'}

There are no foreseen risks to anticipating in this project. The project specifically aims to obtain information about how the service works; no personal health information is collected.

\section{Will I benefit from the study?'}

This study aims to further nursing knowledge and may improve future delivery of emergency psychiatric care; however, it may not directly benefit you. It is anticipated that the findings will be used by St Vincent's hospital as part of on-going development of their service.

8. 'Will taking part in this study cost me anything, and will I be paid? Participation in this study will not cost you anything other than the time to be involved. No payment will be given for participating in the interview.

\section{9. 'How will my confidentiality be protected?'}

Caroline Koia and Dr Katherine Nelson are the only persons who will know whether or not you are participating in this study. Any identifiable information that is collected about you in connection with this study will remain confidential and will be disclosed only with your permission, or except as required by law. Only the researchers named above will have access to your details and results that will be held securely at St Vincent's Hospital in a locked filing cabinet and password protected computer. Data will be destroyed one year later.

\section{What happens with the results?}

If you give us your permission by signing the consent document, we plan to discuss/publish the results in the final thesis. It is intended that one or two articles will be submitted for publication in scholarly journals and that presentations will be given at St Vincent's and at professional conferences. In any publication, information will be provided in such a way that you cannot be identified. Results of the study will be provided to you, if you wish. 
11. 'What should I do if I want to discuss this study further before I decide?'

When you have read this information, the researcher Caroline Koia will discuss it with you and any queries you may have. If you would like to know more at any stage, please do not hesitate to contact her on: Mobile: 0438837156 or Telephone: (02) 83824090

12. 'Who should I contact if I have concerns about the conduct of this study?'

This study has been approved by St Vincent's Hospital HREC. Any person with concerns or complaints about the conduct of this study should contact the Research Office who is nominated to receive complaints from research participants. You should contact them on 02 83822075 and quote: - SVH File Number: 08/164.

Thank you for taking the time to consider this study.

If you wish to take part in it, please sign the attached consent form.

This information sheet is for you to keep.

Researcher

Caroline Koia

Clinical Nurse Specialist

PECC

St Vincent's Hospital, Darlinghurst

NSW 2010

Australia

Tel: 0438837156

e-mail: ckoia@stvincents.com.au

\section{Supervisor}

Dr. Katherine Nelson

Senior Lecturer

Graduate School of Nursing, Midwifery \& Health,

Victoria University of Wellington,

PO Box 600, Wellington 6140

New Zealand

Tel: 00644463 6138, fax 006444635445442

e-mail: kathy.nelson@vuw.ac.nz 


\section{Appendix 3}

VICTORIA UNIVERSITY OF WELLINGTON

Te Whare Wananga o te Upoko o te Ika a Maui
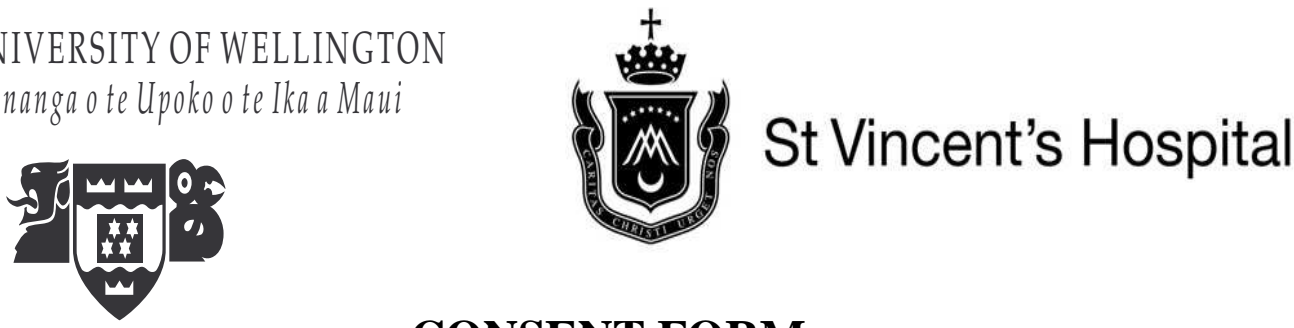

CONSENT FORM

[To be used in conjunction with a Participant Information Sheet]

An Evaluation of the Psychiatric Emergency Care Centre St Vincent's Hospital, New South Wales

I. I.........

of. agree to participate as a subject in the study described in the participant information statement set out above (or: attached to this form).

2. I acknowledge that I have read the participant information statement, which explains why I have been selected, the aims of the study and the nature and the possible risks of the investigation, and the statement has been explained to me to my satisfaction.

3. Before signing this consent form, I have been given the opportunity of asking any questions relating to any possible physical and mental harm I might suffer as a result of my participation and I have received satisfactory answers.

4. I understand that I can withdraw from the study at any time without prejudice to my relationship to the St Vincent's Hospital.

5. I agree that research data gathered from the results of the study may be published, provided that I cannot be identified.

6. I understand that if I have any questions relating to my participation in this research, I may contact Caroline Koia on telephone 0438837156 or (02) 83824090, who will be happy to answer them.

7. I acknowledge receipt of a copy of this Consent Form and the Participant Information Statement. Complaints may be directed to the Research Governance Officer, (020) 8382 2075 and quote SVH File Number: 08/164.

Signature of subject

Signature of investigator

Signature of witness
Please PRINT name

Please PRINT name

Please PRINT name
Date

Date

Date 


\section{Appendix 4}

VICTORIA UNIVERSITY OF WELLINGTON

Te Whare Wananga o te Upoko o te Ika a Maui
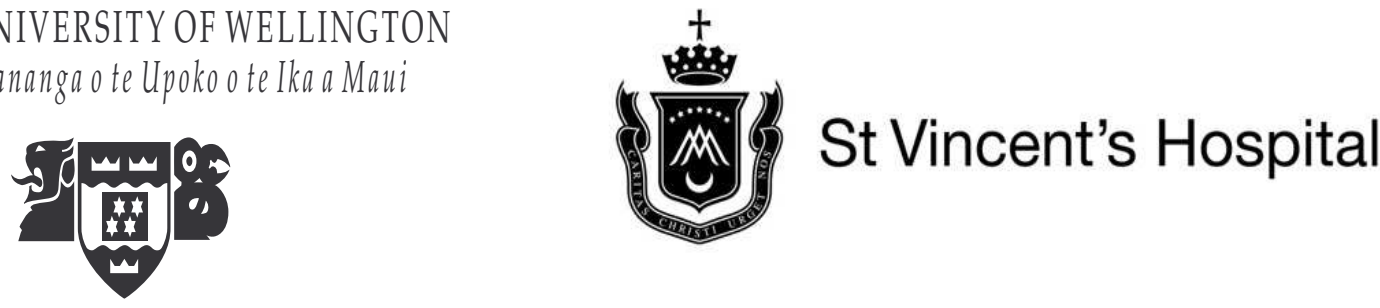

\section{REVOCATION OF CONSENT}

I hereby wish to WITHDRAW my consent to participate in the study described above and understand that such withdrawal WILL NOT jeopardise any treatment or my relationship with ST Vincent's Hospital.

Signature

Date

Please PRINT Name

The section for Revocation of Consent should be forwarded to

Caroline Koia

Psychiatric Emergency Care Centre

St Vincent's Hospital, Darlinghurst

NSW 2010 


\section{Appendix 5}

\section{PECC Nurses Interview Schedule}

The Evaluation of the Psychiatric Emergency Care Centre (PECC) at St Vincent's Hospital, New South Wales

Introduce purpose of interview - To obtain PECC nurses views on how they work within PECC and within the ED, what skills and knowledge they consider are required and utilised in the role, and what they consider works well and what could be improved from a nurse's perspective.

\section{Complete consent procedures}

Questions/Interview prompts

1. How long have you worked in the PECC service?

2. Why did you join the PECC service?

3. What do you consider are the strengths of the PECC service? Why?

4. What do you consider are the weaknesses of the PECC service? Why?

5. If you could change the PECC service what would you change? Why?

\section{Role in ED liaison}

Tell me about a typical shift as an ED PECC liaison nurse

Tell me about a typical patient presentation (please do not use names)

Where did the person come from?

What did you do?

Who did you consult?

What was the outcome? 
Tell me about the presentations you find easy? Why?

Tell me about the presentations you find hard? Why?

What skills do you regularly use in the liaison role?

What knowledge do you regularly use in the liaison role?

What works well and what could be improved in the liaison role?

What supports and structures enable the role to work?

What issues do you encounter that make the role difficult?

How does the role intersect with ED staff?

How does the role intersect with the PECC nurses?

How effective is the role?

Why do you think this? (E.g. reduce time in ED, and reduce ED bed blockage, getting patients to most appropriate services, prevent suicides, support ED skills \& knowledge development)

\section{Role as PECC nurse}

Tell me about a typical shift in PECC

What differences are there between morning, afternoon and night shifts?

Tell me about a typical patient presentation (please do not use names)

Where did the person come from?

What did you do?

Who did you consult?

What was the outcome?

Tell me about the presentations you find easy and why they are easy?

Tell me about the presentations you find hard and why they are hard?

What skills do you regularly use in the PECC role? 
What knowledge do you regularly use in the PECC role?

What works well and what could be improved in PECC?

What are supports and structures make the PECC role work well?

What issues do you encounter that make the PECC role difficult?

How does the role intersect with ED staff?

How does the role intersect with the ED PECC liaison nurse?

How effective is the role? (E.g. getting patients to most appropriate services, preventing suicides, relieving pressure on ED, supporting people to stay in the community)

Why do you think this?

\section{Supervision}
a. What are the typical areas that you need clinical advice on?
b. Where do you go for this advice?
c. What supervision do you receive?

\section{Education skills and knowledge}
a. What are your nursing qualifications?
b. What postgraduate study?
c. What mental health experience did you have prior to the PECC role?
d. What areas would you like more education on?

\section{Any other comments}

Thank participants and invite them to contact you if anything to add 


\section{ED Nurse Interview Schedule}

The Evaluation of the Psychiatric Emergency Care Centre (PECC) at the St Vincent's Hospital, New South Wales

Introduce purpose of interview - To obtain an ED staff perspective on how the PECC liaison nurse role intersects with ED and what works well and what could be improved.

Complete consent procedures

Questions/Interview prompts

1. What is your position in ED?

2. How long have you worked here at St Vincent's?

3. What do you understand is the role of the ED PECC liaison nurse?

4. What contact do ED staff typically have with the ED PECC liaison nurse?

5. When and why do ED staff use the ED PECC liaison nurse?

6. What services does the ED PECC liaison nurse provide?

7. What do you consider are the strengths of the ED PECC liaison role? Why?

8. What do you consider are the weaknesses of the ED PECC liaison role? Why?

9. If you could change the ED PECC liaison role service what would you change? Why?

10. How effective is the ED PECC liaison role? Why?

11. Any other comments about the ED PECC liaison role or about the PECC service generally

Thank participants and invite them to contact you if anything to add 


\section{Appendix 7}

\section{Consumer Representative Interview Schedule}

The Evaluation of the Psychiatric Emergency Care Centre (PECC) at St Vincent's Hospital, New South Wales

Introduce purpose of interview - To obtain consumer perspective on how the PECC service works, what works well and what could be improved.

Complete consent procedures

Questions/Interview prompts

1. What is your role in the consumer group?

2. What engagement with the PECC service has the consumer group had?

3. What does the consumer group understand is the role of the PECC service?

PECC has two roles, one is the short stay service (PECC) and one is an ED PECC liaison nurse role Will first ask about the Short stay service, and then about ED

4. How important is the presence of the PECC service for consumers? Why?

5. What does the consumer group consider are the strengths of the PECC service? Why?

6. What does the consumer group consider are the weaknesses of the PECC service? Why?

7. If consumers could change the PECC service what would they change? Why?

8. How effective do consumers consider the PECC service is? Why? 
9. How important is having a PECC liaison nurse in ED?

10. What works well for consumers with this role? Why?

11. What could be improved with this role? Why?

12. What are the gaps in service for people experiencing a mental health crisis?

13. Any other comments about the ED PECC liaison role or about the PECC service generally

Thank participants and invite them to contact you if anything to add 


\title{
Appendix 8
}

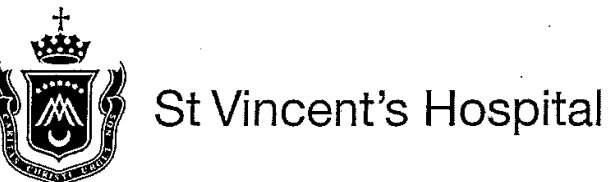

\author{
A FACLITYY OF ST VINCENT'S \\ \& MATER HEALTH SYCNEY \\ ST VINCENT'S HOSPITAL SYDNEY LTD \\ ABN 77054038872 \\ MENTAL HEALTH SERVICE \\ EXECUTIVE OFFICE \\ 299 FORBES STREET 2010 \\ DARLINGHURST NSW 2010 \\ $T+61283821823$
}

$19^{\text {th }}$ September 2008

The Ethics Committees

University of Victoria - New Zealand

St Vincent's Hospital - Sydney

I write to support and approve the undertaking of research in the St Vincent's Mental Health Service by Caroline Koia CNS involving an "Evaluation of the St Vincent's Hospital Psychiatric Emergency Care Centre.

This research will help us to understand how the service is working and improve the quality of care delivered to patient's utilizing it.

Yours sincerely,

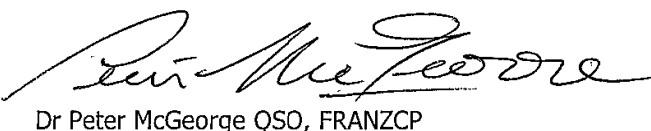




\section{Appendix 9}

$+$

(Mincent's Hospital

26 November 2008

Caroline Koia

Psychiatric Emergency Care Centre

St Vincent's Hospital

390 Victoria St

Darlinghurst NSW 2010

\section{Dear Caroline}

SVH File Number: 08/164

Project Title: Evaluation of the Psychiatric Emergency Care Centre (PECC) at St Vincent's Hospital, New South Wales.

Thank you for submitting the above project for review. Based on the information you have provided and in accordance with the following NHMRC guidelines; National Statement 2007 - Section 5 Institutional Responsibilities and "When does quality assurance in health care require independent ethical review?" (2003), this project has been assessed as negligible risk and is therefore exempt from full HREC review.

I am pleased to advise that the on 25 November 2008 the HREC Executive on behalf of the Executive Director granted authorisation for the above project to commence at St Vincent's Hospital.

The documents approved for this project are

- Participant Information Statement and Consent Form Version - Consumers Version 3 dated 25 November 2008 ;

- Participant Information Statement and Consent Form Version - Service Providers (no version or date);

- Consumer Representative Interview Schedule (no version or date);

- PECC Nurse Interview Schedule; and

- ED Staff Interview Schedule.

Please note the following conditions of approval:

1. This approval is valid for five years, and the Committee requires that you furnish it with annual reports on the projects progress beginning in November 2009. Please notify the HREC Executive in writing when this project is completed.

2. The Investigator will immediately report anything which might warrant review of ethical approval of the project in the specified format, including unforeseen events that might affect continued ethical acceptability of the project and any complaints made by participants regarding the conduct of the project.

3. Proposed changes to the research protocol, conduct of the research, or length of approval will be provided to the HREC Executive for review, in the specified format.

4. The HREC Executive will be notified, giving reasons, if the project is discontinued before the expected date of completion.

Page 1 of 2 
Please note that for multi-site projects authorisation needs to be obtained from each participating institution.

If you have any queries relating to the above please contact the Research Office on 8382 2075.

Yours sincerely

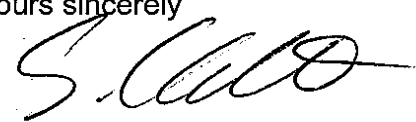

Sarah Charlton

Executive Officer

Research Office

08.164.2 


\section{References}

Australian Health Ministers. (1992a). National Mental Health Policy: Canberra: Australian Government Publishing Service.

Australian Health Ministers. (1992b). National Mental Health Plan. Canberra: Australian Government Publishing Service.

Australian Health Ministers Advisory Council National Working Group. (1997). National Standards for Mental Health Services. Canberra: Australian Government Publishing Service.

Australian Health Ministers. (1998). Second National Mental Health Plan: Mental Health Branch, Commonwealth Department of Health and Family Services, 1998.

Australian Health Ministers. (2003). National Mental Health Plan 2003-2008. Canberra: Australian Government Publishing Service.

Beech, B., Parry, L., \& Valiani, D. (2000). A pilot project to determine the demand for an utility of an out-of-hours psychiatric service run by on-call psychiatric nurses in an A\&E department. Journal of Psychiatric and Mental Health Nursing, 7, 547553.

Brendon, S. \& Reet, M. (2000). Establishing a mental health nurse service: Lessons for the future. Nursing Standard, 14, 43-47.

Brown, JF. (2005). Psychiatric emergency services: A review of the literature and a proposed research agenda. Psychiatric Quarterly, 7(2), 139-165.

Bryant, J., Forster, J., McNamara, P. \& Sharrock, J. (2007). You are not alone: Results of the 2005 Australian Consultation-Liaison Nurses Survey. The Australian College of Mental Health Nurses Consultation-Liaison Special Interest Group. Retrieved May 28, 2008 from http://www.acmhn.org/CLSIG-surveyreport.pdf

Calman, K. C. (1993). Hospital Doctors: Training for the future. The Report of the Working Group on Specialist Medical Training. London: HSMO

Callaghan, P., Eales, S., Leigh, L., Smith, A. \& Nichols, J. (2001). Characteristics of an accident and emergency liaison mental health service in East London. Journal of Advanced Nursing, 35(6), 812-818.

Callaghan, P., Eales, S., Coates, T., \& Bowers, L. (2003). A review of research on the structure, process and outcome of liaison mental health services. Journal of Psychiatric and Mental Health Nursing, 10, 155-165.

Clarke, A. (2001). Evaluation research in nursing and health care, Nurse Researcher, $8(3), 4-14$.

Clarke, D. E., Hughes, 1., Browne, A. M. \& Motluk, L. (2005) Psychiatric emergency nurses in the emergency department: The success of the Winnipeg, Canada experience. Journal of Emergency Nursing, 31(4), 351-356.

Clinton, M. \& Hazelton, M. (2000). Scoping mental health nursing education. Australian and New Zealand Journal of Mental Health Nursing, 9, 2-10. 
Cox, C., L. (2000). The nurse consultant: an advanced nurse practitioner? Nursing Times, $96,48$.

Currier, G. W., \& Allen, M. (2003). Organization and function of academic psychiatric emergency services. General Hospital Psychiatry, 25(2), 124-9.

Eales, S., Callaghan, P., \& Johnson, B. (2006). Service users and other stakeholders' evaluation of a liaison mental health service in an accident and emergency department and a general hospital setting. Journal of Psychiatric \& Mental Health Nursing, 13, 70-77.

Ellis, R. \& Hogard, E. (2006). The Trident: A three-pronged method for evaluating clinical, social and educational innovations. Retrieved on October 13, 2008 from http://evi.sagepub.com at University of New South Wales.

Ford, E. (1998). How collaboration between general and mental health nurses can benefit consumers. Proceedings of the Australian and New Zealand College of Mental Health Nurses Inc $24^{\text {th }}$ Conference, Australia, 401-405.

Frank, A., Fawcett, L. \& Emmerson, B. (2005). Development of Australia's first psychiatric emergency centre. Australian Psychiatry, 13(3), 266-272.

Garling, P. (2008). Final Report of the Special Commission of Inquiry: Acute Care Services in NSW Public Hospitals Vol 2. Retrieved April 5, 2009 from http:www.lawlink.nsw.gov.au/acsinquiry

Gillettte, J., Bucknell, M. \& Meegan, E. (1996). Evaluation of psychiatric nurse clinical consultancy in emergency departments project. Bundoora: Faulty of Nursing Bundoora Royal Melbourne Institute of Technology.

Hall, J. (2004). Pluralistic evaluation: A situational approach to service evaluation. Journal of Nursing Management, 12, 22-27.

Happell, B. \& Sharrock, J. (2002). Evaluating the role of a psychiatric consultationliaison nurse in the Australian general hospital. Issues in Mental Health Nursing, 23, 43-60.

Happell, B., Summers, M. \& Pinikahana, J. (2002). The triage of psychiatric patients in the hospital emergency department: A comparison between emergency department nurses and psychiatric nurse consultants. Accident and Emergency Nursing, 10, 65-71.

Hatchett, R. (2003). The emergence of the modern nurse led clinic. In Nurse led clinics practice issues, ed. R. Hatchett, 1-26. London: Routledge.

Hawe, P., Degeling, D. \& Hall, J. (1990). Evaluating health promotion, a Health Worker Guide. Sydney: MacLennan \& Petty.

Hayes, J., \& Harrison, A. (2003). Consultant nurses in mental health: A discussion of the historical and policy context of the role. Journal of Psychiatric and Mental Health Nursing, 11, 185-188.

Hughes, L. G., \& Clarke, D.E. (2002). Psychiatric nurses in hospital emergency departments. Canadian Nurse, 98, 23-26. 
Karshmer, J. (1997). Role of the psychiatric clinical nurse specialist in the emergency department. A Journal for Advanced Nursing Practice, 11(6), 264-268.

Koch, T. (2003). Collaborative evaluation research. In Schneider, Z., Elliot, D., Lo Biondo-Wood, G., \& Haber, J. (Eds.). Nursing research: Methods, critical appraisal and utilization. (pp 232-245), (2 ${ }^{\text {nd }}$ ed.). Sydney: Mosby.

Mendoza, J. (2006) Psychiatric Emergency Care Centres (PECCs): Show me the evidence! In Mental Health Council of Australia Newsletter. Canberra: Mental Health Council of Australia.

Mental Health Coordinating Council, (2006). The lowdown on PECCs. View from the Peak. Retrieved on August 182008 from http://www.mhcc.org.au/documents/Winter2006.pdf

Meyers, W. (1981). The evaluation enterprise. London: Sage.

McArthur, M., \& Montgomery, P. (2004). The experience of gatekeeping: A psychiatric nurse in an emergency department. Issues in Mental Health Nursing, 25, 487-501.

McClintock, K. \& Ihimaera, L.V. (2007). Maori mental health need in emergency departments. Palmerston North: Te Rau Matatini.

McDonough, S., Wynaden, D., Finn, M., McGowan, S., Chapman, R. \& Hood, S. (2004). Emergency department mental health triage consultancy service: An evaluation of the first year of the service. Accident and Emergency Nursing, 12(10), 31-38.

McEvoy, P. (1998). Psychiatric at the front line: CPNs working outside regular hours in an inner-city A \& E department. Journal of Psychiatric and Mental Health Nursing, 5, 445-45

Minarik, P. A. \& Neese, J.B. (2002). Essential educational content for advanced practice in psychiatric consultation liaison nursing. Archives of Psychiatric Nursing, 16(1), 3-15.

Morgan, V. \& Coleman, M. (2000). An evaluation of the implementation of a liaison service in an A\&E department. Journal of Psychiatric and Mental Nursing, 7, 391-397.

Nelson, T. D., Steel, R. G., \& Mize, J. A. (2006). Practitioner attitudes toward evidencebased practice: Themes and challenges. Administration Policy in Mental Health and Mental Health Services Research, 33, 398-409.

New South Wales (NSW) Department of Health. (1997). New South Wales Standards for Mental Health Services. NSW Health Department.

New South Wales (NSW) Health Department. (1998). Working group for mental health care in emergency departments, final report and recommendations. Sydney: State Health Publications.

New South Wales Health. (2004). Your Guide to MH-OAT: Clinicians reference guide to NSW mental health Outcomes and Assessment Tools. Sydney: NSW Health Department. 
New South Wales (NSW) Department of Health. (2006). NSW: A new direction for Mental Health. NSW Health.

New South Wales Health. (2006). South Eastern Sydney Illawara: Area Governance Manual. Retrieved January 12, 2008 from http://sesiweb.Ian.sesahs.nsw.gov.au

New South Wales Health. (2007). Psychiatric Emergency Care Centre (PECCs) the first twelve months. Sydney: State Health Publications.

Owen, J. M. (2006). Program evaluation forms and approaches. ( $3^{\text {rd }}$ Ed.). Australia: Allen \& Unwin.

Patton, M.Q. (1990). Qualitative evaluation and research methods. California: Sage.

Patton, M. Q. (1997). Utilization - focused evaluation. ( $3^{\text {rd }}$ Ed.). Thousand Oak CA: Sage.

Peterson, C. (1997). Quantitative approaches to evaluation in health care. In Gardner, H. (Ed.), Health Policy in Australia (pp. 98-115). Melbourne: Oxford University Press.

Polit, D. F. \& Beck, C, T. (2006). Essentials of nursing research: Methods, appraisal, and utilization. $\left(6^{\text {th }}\right.$ Ed.). Philadelphia: Lippincott Williams \& Wilkins.

Polit-OHara, D. F., \& Hungler, B. P. (1995). Nursing research: Principles and methods. Philadelphia: Lippincott Williams \& Wilkins.

Regaisis, K. (2005). Perspectives on psychiatric consultation liaison nursing: Bridging the gap. Perspectives in Psychiatric Care, 41(4), 197-198.

Roberts, D. (1997). Liaison mental health nursing: Origins, definitions and prospects. Journal of Advanced Nursing, 25, 101-108.

Roberts, D. (2002). Working models for practice. In S. Regal \& D. Roberts (Eds.), Mental health liaison: A handbook for nurses and health professionals. (pp. 23-42). Edinburgh: Harcourt Publishers Limited.

Roberts, D. \& Whitehead, L. (2002). Liaison mental health nursing: an overview of its development and current practice. In S. Regal \& D. Roberts, (Eds.), Mental health liaison: A handbook for nurses and health professionals. (pp. 43-63). Edinburgh: Harcourt Publishers Limited.

Robson, C. (1993). Real world research: A source for social scientists and practitionerresearchers. Oxford; Cambridge, MA: Blackwell.

Ryan, J. M., Clemment, S., \& Snelson, A. (1997). Role of a psychiatric liaison nurse in an A \& E department. Accident and Emergency Nursing, 5, 152-155.

Sharrock, J. (2006). Perspectives on psychiatric consultation liaison nursing: A perspective from the southern hemisphere. Perspectives in Psychiatric Care, 42(2), 137-139.

Sharrock, J. \& Happell, B. (2000). The role of the psychiatric consultation-liaison nurse in the general hospital. Australian Journal of Advanced Nursing, 18(1), 34-39. 
Sharrock, J. \& Happell, B. (2006). Competence in providing mental health care: A grounded theory analysis of nurses' experiences. Australian Journal of Advanced Nursing, 24, (2), 9-5.

Sharrock, J., Bryant, J., McNamara, P., Foster, J., \& Happell, B. (2008). Exploratory study of mental health consultation-liaison nursing in Australia: Part 1 demographics and role characteristics. International Journal of Mental Health Nursing, 17, 180-188.

Sinclair, L., Hunter, R., Hagan, S., Nelson, D. \& Hunt, J. (2006). How effective are mental health nurses in A\&E departments. Emergency Medicine Journal, 23, 687692.

Smart, D., Pollard, C. \& Wagpole, B. (1999). Mental health triage in emergency medicine. Australian and New Zealand Journal of Psychiatry, 33, 57-66.

St Vincents Hospital Emergency Department NSW (2007). Rapid Tranquilization Guidelines. Retrieved May 30, 2008 from http:wwwsvh.stvincents.com.au/MHS/pdf/tranquillisation11.pdf

St Vincents Mental Health Service NSW. (2008a). Psychiatric Emergency Care Centre (PECC).Operational Manual. Retrieved January 20, 2008 from http:wwwsvh.stvincents.com.au/MHS/.

St Vincents Mental Health Service NSW. (2008b). St Vincent's Mental Service Manual. Retrieved April 142008 from http://wwwsvh.stvincents.com.au/MHS/

St Vincents Mental Health Service NSW (2008c) Count Me in News. Issue No3, August 2008, (pp1-4). St Vincents Mental Health Service.

St Vincents Mental Health Service NSW. (2009). St Vincent's MHS Action Plan for Patient Journey Interview Feedback. St Vincents Mental Health Service

Thompson, C. (2005). Caring for people with mental problems who present at the emergency department: A nurse educator's journey. Unpublished master's research report, Victoria University of Wellington, Wellington, New Zealand.

Trochim, M.K. (2006). Research methods: The concise knowledge base. Cincinnati: Atomic Dog Publishing.

University of Technology Sydney. (2003). New frontier for mental health nursing. Retrieved July15, 2007 from http:uts.edu.au/new/releases/2003/August/13htm.

Unrau, Y. A., Krysik, J.L., \& Grinnell, R. M, Jr. (2005). Glossary. In Grinnell, R. M, Jr. \& Unrau, Y. A., (Eds.). Social work research and evaluation quantitative and qualitative approaches. ( $7^{\text {th }}$ Ed.). (pp.474). Oxford: Oxford University Press, Inc.

Vidaro, C.L., Earp, J. L., \& Alpeter, M.A. (1997). Designing a process evaluation for a comprehensive breast cancer screening intervention: Challenges and opportunities. Evaluation and Program Planning, 2(3), 237-249. 
Walsh, K., Duke, J., Foureur, M., \& McDonald, L. (2007). Designing an effective plan: A tool for understanding and planning evaluations for complex nursing contexts. Contemporary Nurse, 25, 136-145.

Wand, T. (2004). Mental health liaison nursing in the emergency department: on-site expertise and enhanced coordination of care. Accident and Emergency Nursing, 22(2), 25-31.

Wand, T. \& Fisher, J. (2006). The mental health nurse practitioner in the emergency department: An Australian experience. International Journal of Mental Health Nursing, 15, 201-208.

Wand, T. \& Shaecken, P. (2006). Consumer evaluation of a mental health liaison nurse service in the Emergency Department. Accident and Emergency Nursing, 9, 166176.

Wand. T. \& White, K. (2007). Examining models of mental health service delivery in the emergency department. The Royal Australian and New Zealand College of Psychiatrist, 41, 784-791.

Wand, T., White, K. \& Patching, J. (2008). Refining the model for an emergency department-based mental health nurse practitioner outpatient service. Nursing Inquiry, 15(3), 231-241.

Webster, S. \& Harrison, L. (2004). The multi-disciplinary approach to mental health crisis management: An Australian example. Journal of Psychiatric and Mental Health Nursing, 11, 21-29

Wimbush, E. \& Watson, J. (2000). An evaluation framework for health promotion: Theory, quality, and effectiveness. Evaluation, 6: 301-321. Retrieved January 20, 2008 from http://evi.sagepub.com at University of New South Wales 